\title{
Assessment of Anabaena sp. strain PCC 7120 as a heterologous expression host for cyanobacterial natural products: production of lyngbyatoxin $\mathbf{A}$.
}

\author{
Patrick Videau ${ }^{1}$, Kaitlyn N. Wells ${ }^{2}$, Arun J. Singh ${ }^{1}$, William H. Gerwick ${ }^{3}$, Benjamin \\ Philmus ${ }^{1 *}$ \\ ${ }^{1}$ Department of Pharmaceutical Sciences, College of Pharmacy, Oregon State University, \\ Corvallis, OR 97331 \\ ${ }^{2}$ Undergraduate Honors College, Oregon State University, Corvallis, OR 97331 \\ ${ }^{3}$ Center for Marine Biotechnology and Biomedicine, Scripps Institution of Oceanography \\ and Skaggs School of Pharmacy and Pharmaceutical Sciences, University of California, \\ San Diego, La Jolla, CA 92093 \\ *Correspondence: B. Philmus, Department of Pharmaceutical Sciences, College of \\ Pharmacy, Oregon State University, 203 Pharmacy Bldg., Corvallis, OR 97331. \\ Email: benjamin.philmus@oregonstate.edu
}

\section{Supplementary Figures and Tables}

Abbreviations: Anabaena 7120, Anabaena sp. strain PCC 7120 


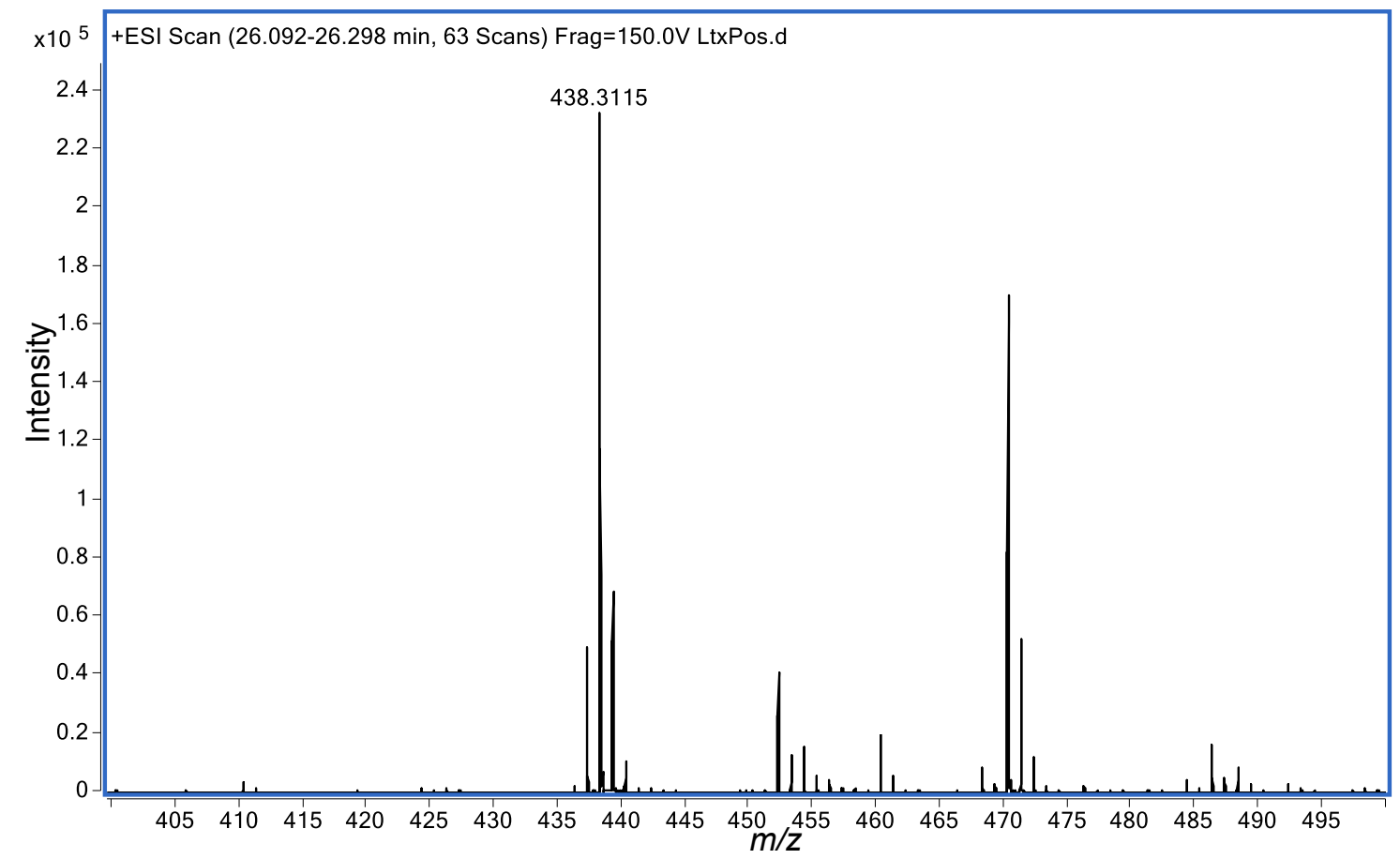

Supplementary Figure 1. High resolution ESI mass spectrum (positive mode) of lyngbyatoxin A produced by Anabaena 7120 . The protonated ion appears at $\mathrm{m} / \mathrm{z}$ 438.1115 (calc. 438.115, 0 ppm error). 

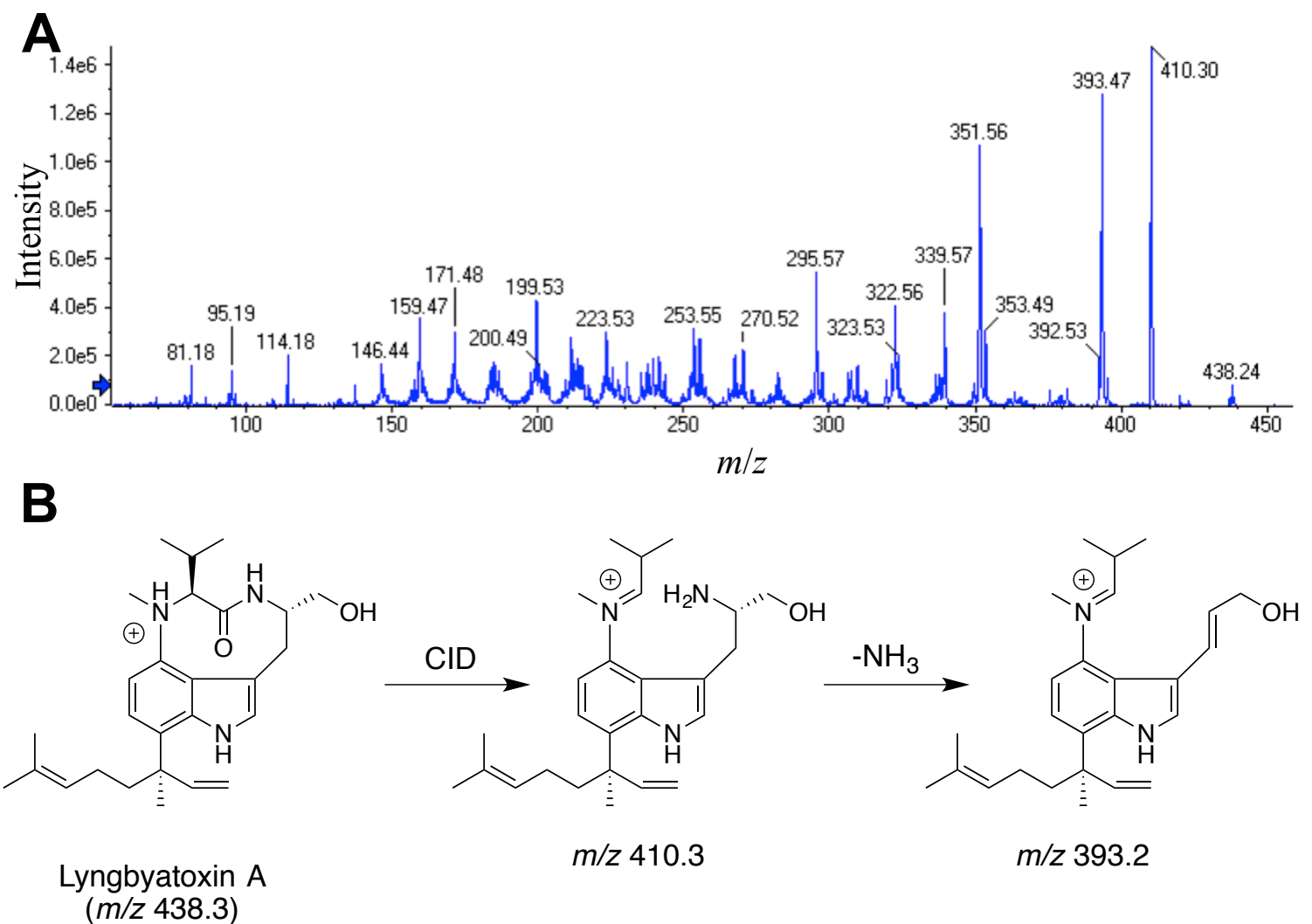

Supplementary Figure 2. (A) Low resolution LC-MS/MS fragmentation of lyngbyatoxin A. The protonated ion $(\mathrm{m} / \mathrm{z} 438.3)$ was isolated and fragmented using $45 \pm$ $10 \mathrm{~V}$. (B) Proposed fragmentation pattern of lyngbyatoxin A. 


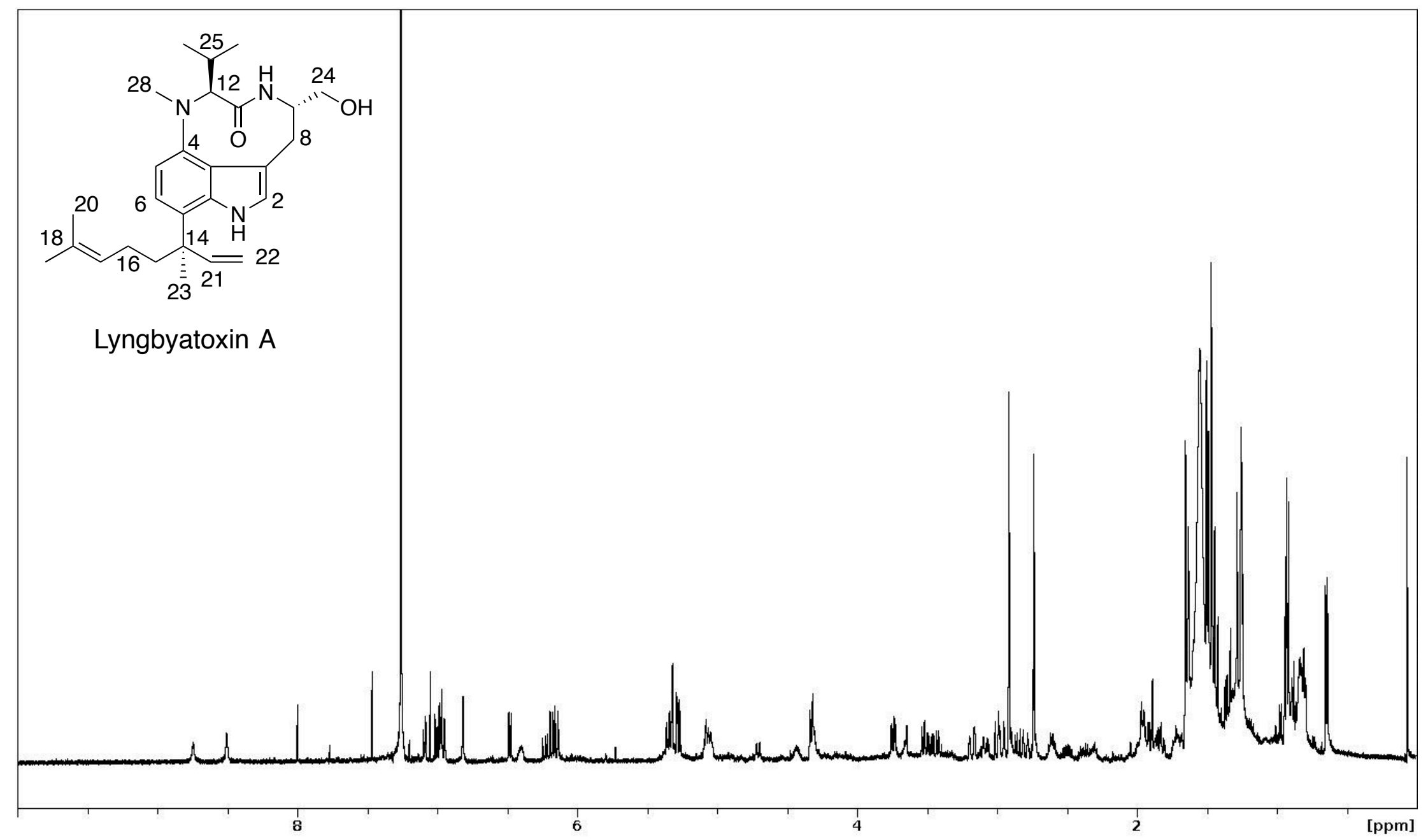

Supplementary Figure 3. ${ }^{1} \mathrm{H}$ NMR spectrum $(500 \mathrm{MHz})$ of purified lyngbyatoxin A isolated from Anabaena 7120 . The complex NMR spectrum is due to peak doubling caused by the presence of conformers as previously noted. ${ }^{1,2}$ 


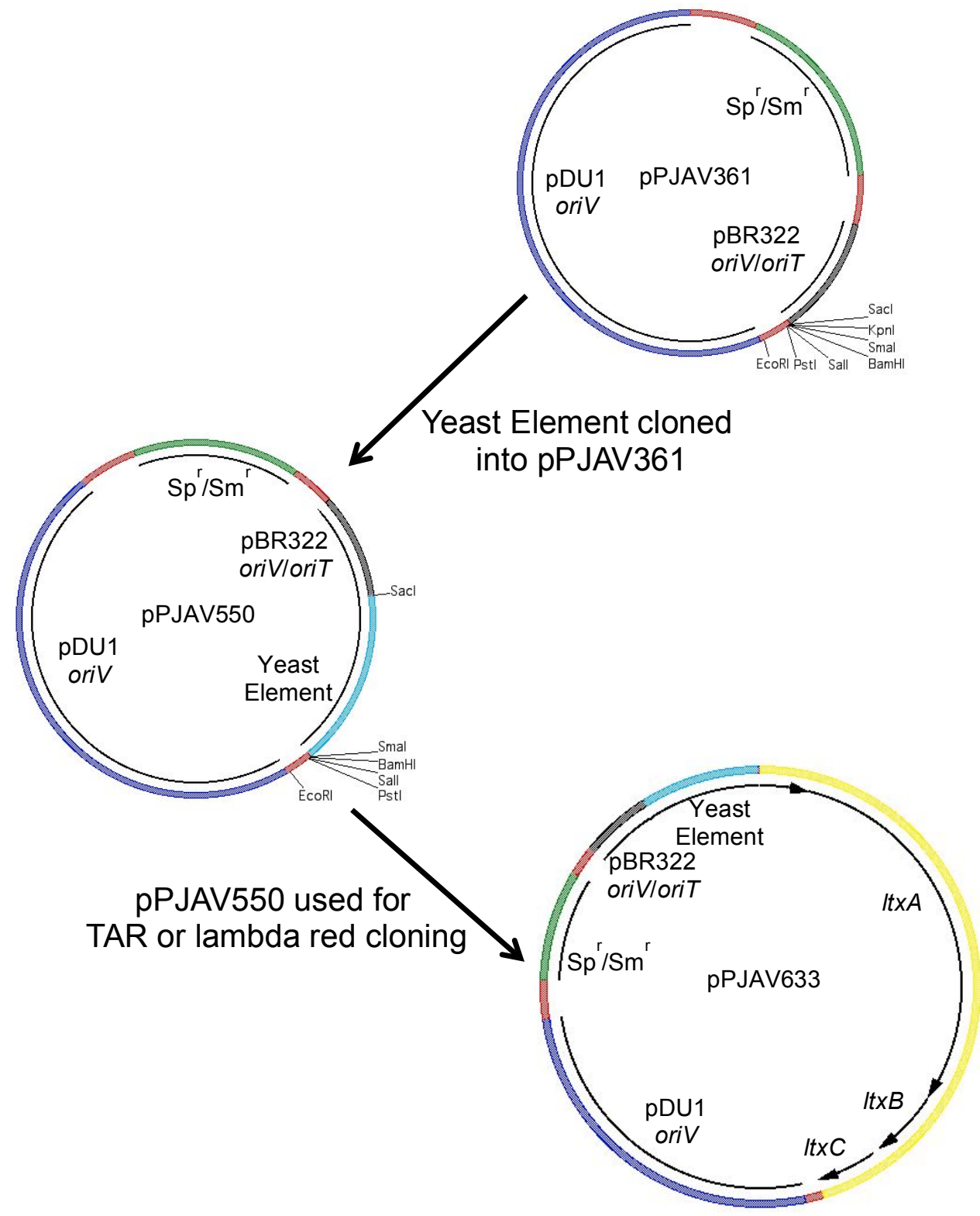

Supplementary Figure 4. Creation and utilization of the cloning vector pPJAV550 employed in this study. 


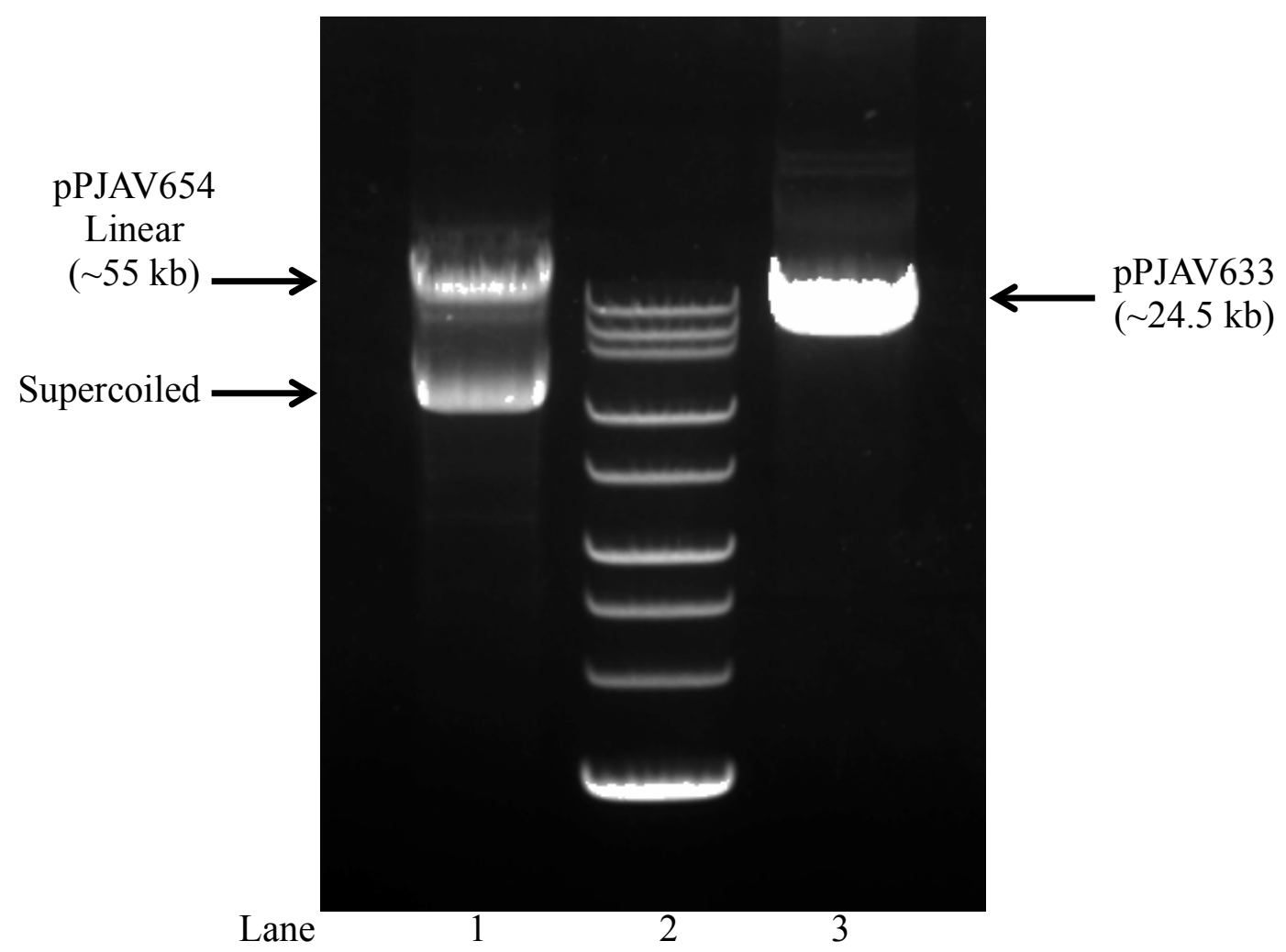

Supplementary Figure 5. Depiction of pPJAV654 (pPJAV550 with the entire $M$. producens fragment from fos-DE3-86; lane 1) and pPJAV633 (pPJAV550 with ltxA-C; lane 3) as compared to the Quick-Load $1 \mathrm{~kb}$ Extend DNA Ladder (New England Biolabs; lane 2) run on a $0.5 \%$ agarose gel. The top three bands of the ladder from top to bottom: $48 \mathrm{~kb}, 20 \mathrm{~kb}, 15 \mathrm{~kb}$. The lowest band of the ladder shown is $3 \mathrm{~kb}$. 

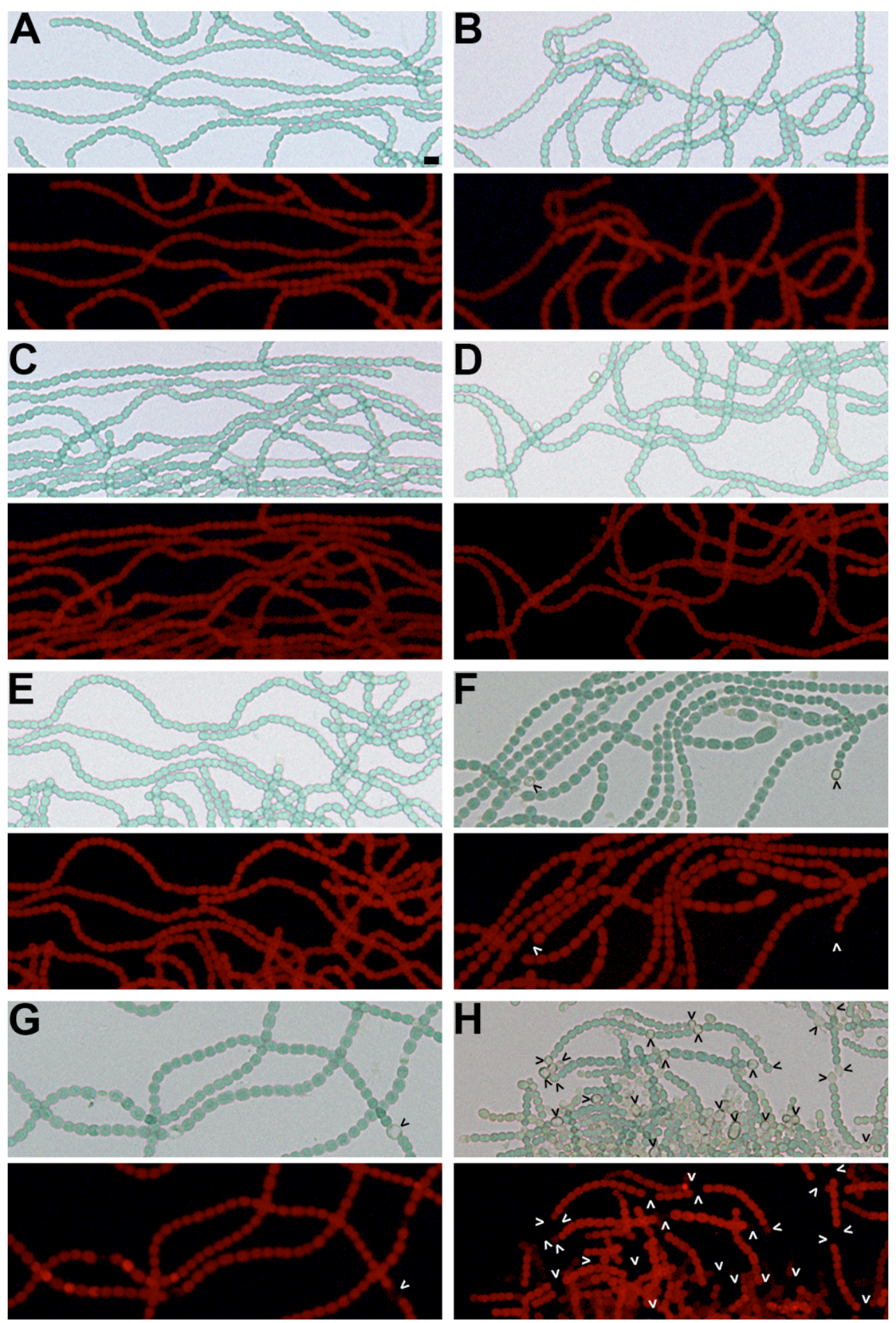

Supplementary Figure 6. Phenotypic assessment of the nitrogen status of Anabaena 7120 cultures harboring pPJAV500 after one (A, B), two (C, D), three (E, F), and four $(\mathrm{G}, \mathrm{H})$ weeks of growth on BG-11 (A, C, D, G) or BG-11( $\left.\mathrm{NH}_{4}\right)(\mathrm{B}, \mathrm{D}, \mathrm{F}, \mathrm{H})$ plates. Nitrogen-limited conditions give rise to heterocysts. Brightfield, top; red autofluorescence, bottom. Carets indicate heterocysts that display the typical loss of autofluorescence. Bar, $10 \mu \mathrm{m}$. 


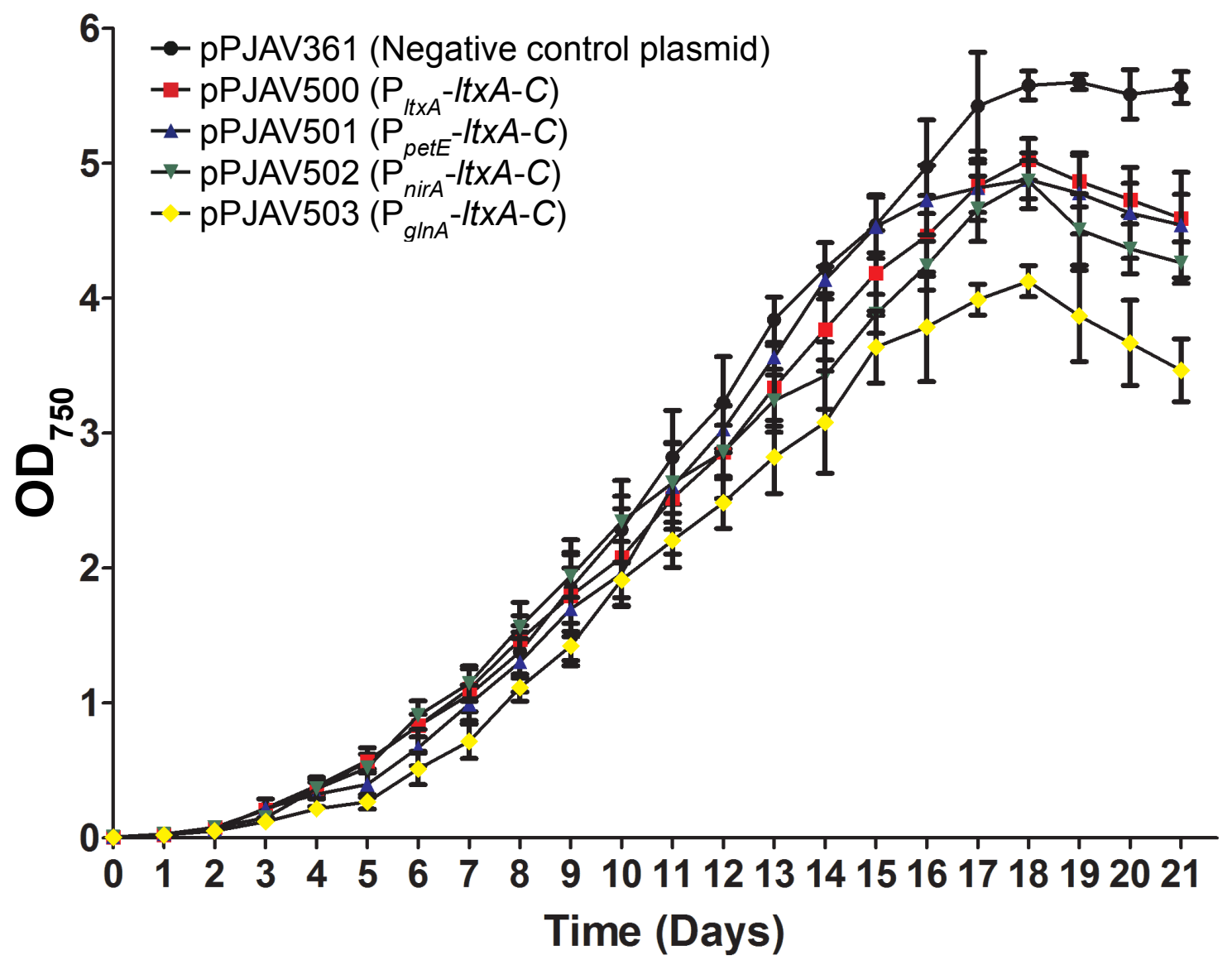

Supplementary Figure 7. Growth of Anabaena 7120 strains harboring replicative plasmids expressing $l t x A-C$ from the native (pPJAV500; red squares) and the petE (pPJAV501; blue triangles), nirA (pPJAV502; green triangles), and $\ln A$ (pPJAV503; yellow diamonds) promoters and an empty control vector (pPJAV361; black circles). Anabaena 7120 strains were grown in BG-11 in triplicate and $\mathrm{OD}_{750}$ measurements were taken daily. Data is presented as the average \pm the standard deviation. 

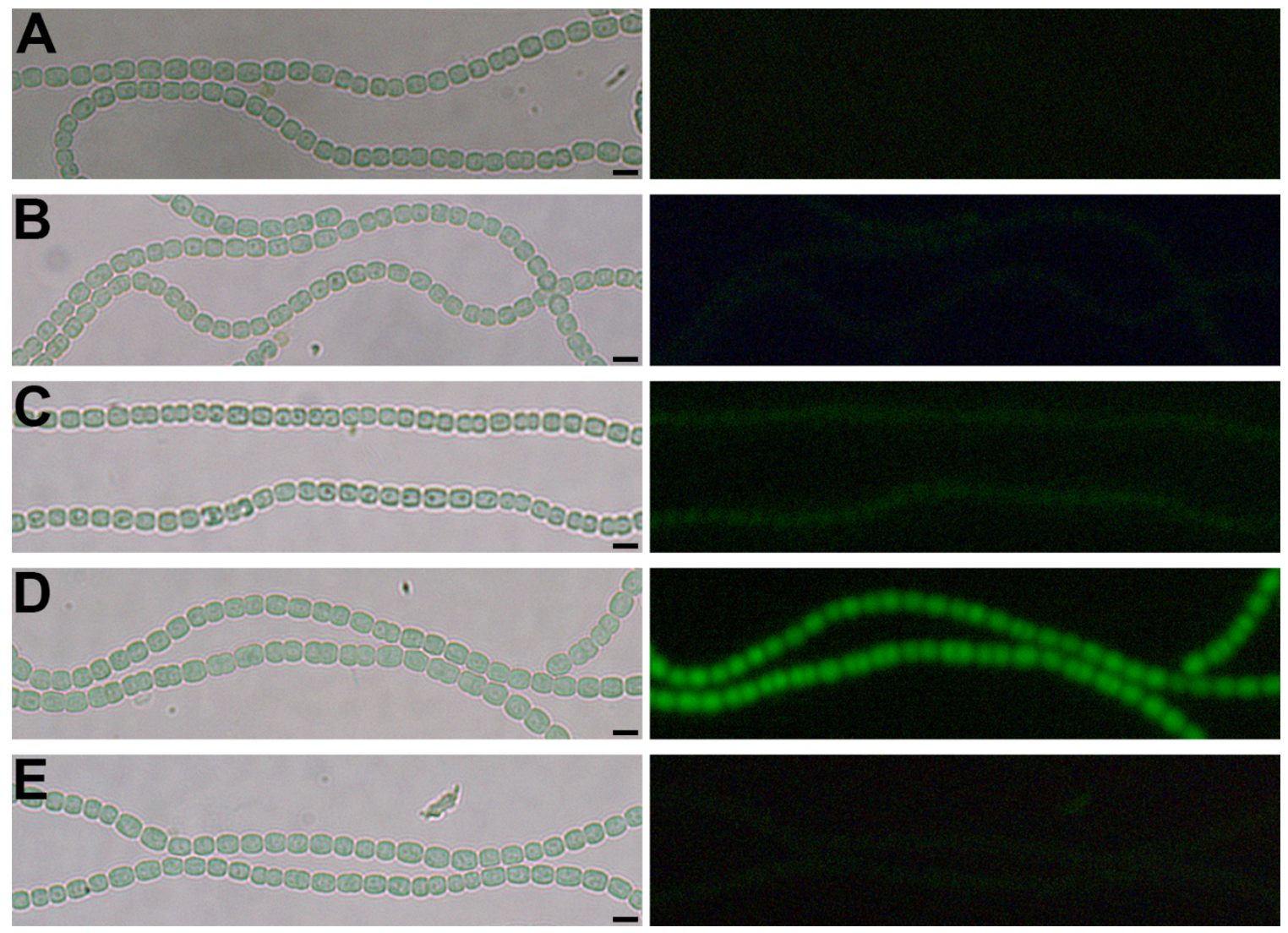

Supplementary Figure 8. Promoters from natural product gene clusters derived from marine cyanobacteria are recognized by Anabaena 7120. Anabaena 7120 harboring transcriptional fusions of the $\operatorname{ltx} A(\mathrm{~B}), \operatorname{ltx} D(\mathrm{C}), \operatorname{cur} A(\mathrm{D})$, and patA (E) promoter regions fused to $g f p$ were cultured in BG-11 medium and representative brightfield (left) and fluorescence (right) micrographs are presented. Green fluorescence is compared to the promoterless $g f p$ in pAM1956 (A). Bar, $10 \mu \mathrm{m}$. 

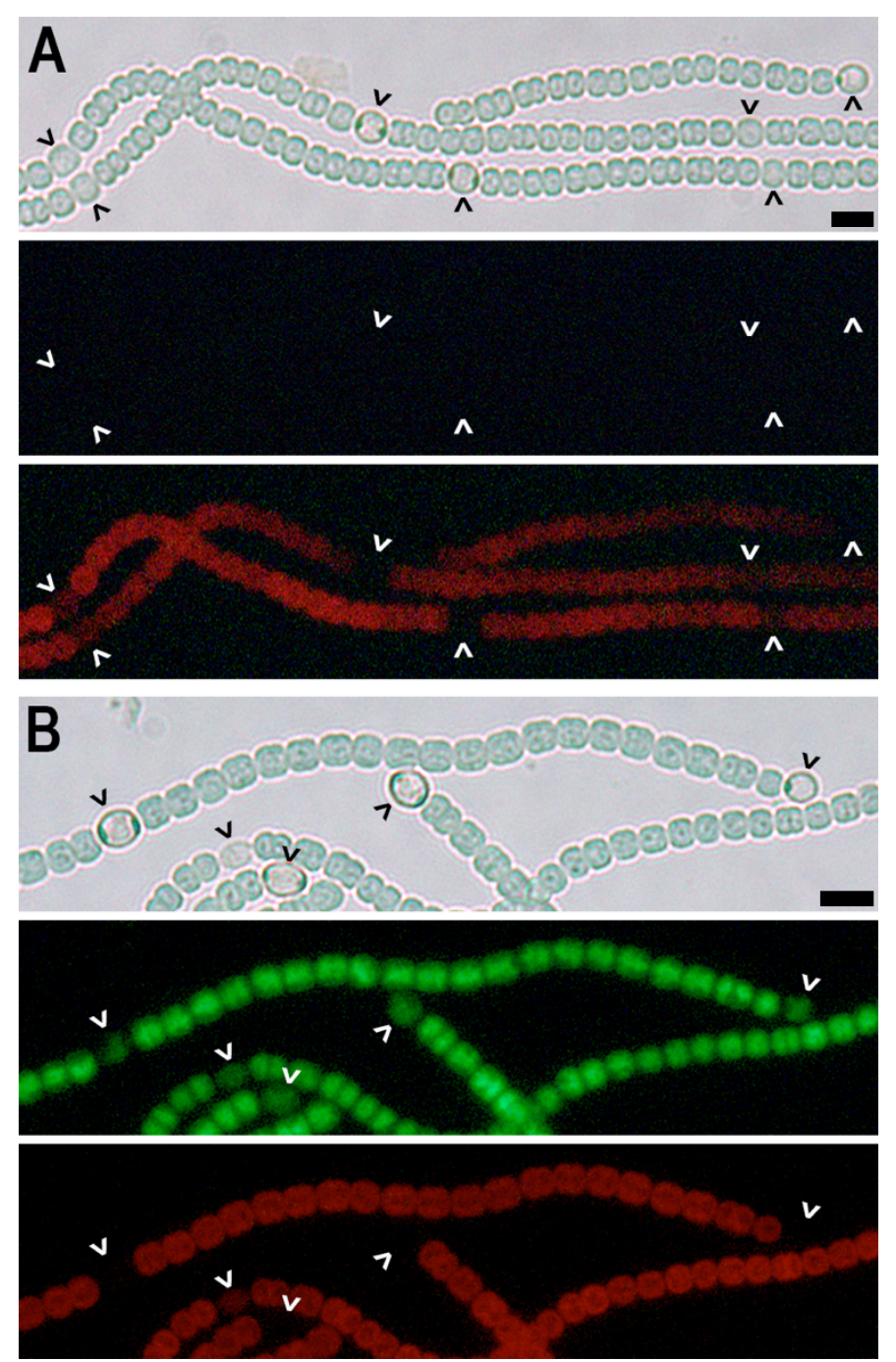

Supplementary Figure 9. Promoters from marine cyanobacteria are expressed in both vegetative and heterocyst cell types of Anabaena 7120. Anabaena 7120 harboring a promoterless gfp in pAM1956 (A) or a $\mathrm{P}_{c u r A^{-}} g f p(\mathrm{~B})$ transcriptional fusion, representative of all promoter fusions, $24 \mathrm{~h}$ after the removal of combined nitrogen to induce heterocyst formation. Brightfield, top; green fluorescence from GFP, middle; red autofluorescence, bottom. Carets indicate heterocysts that display the typical loss of autofluorescence. Bar, $10 \mu \mathrm{m}$. 

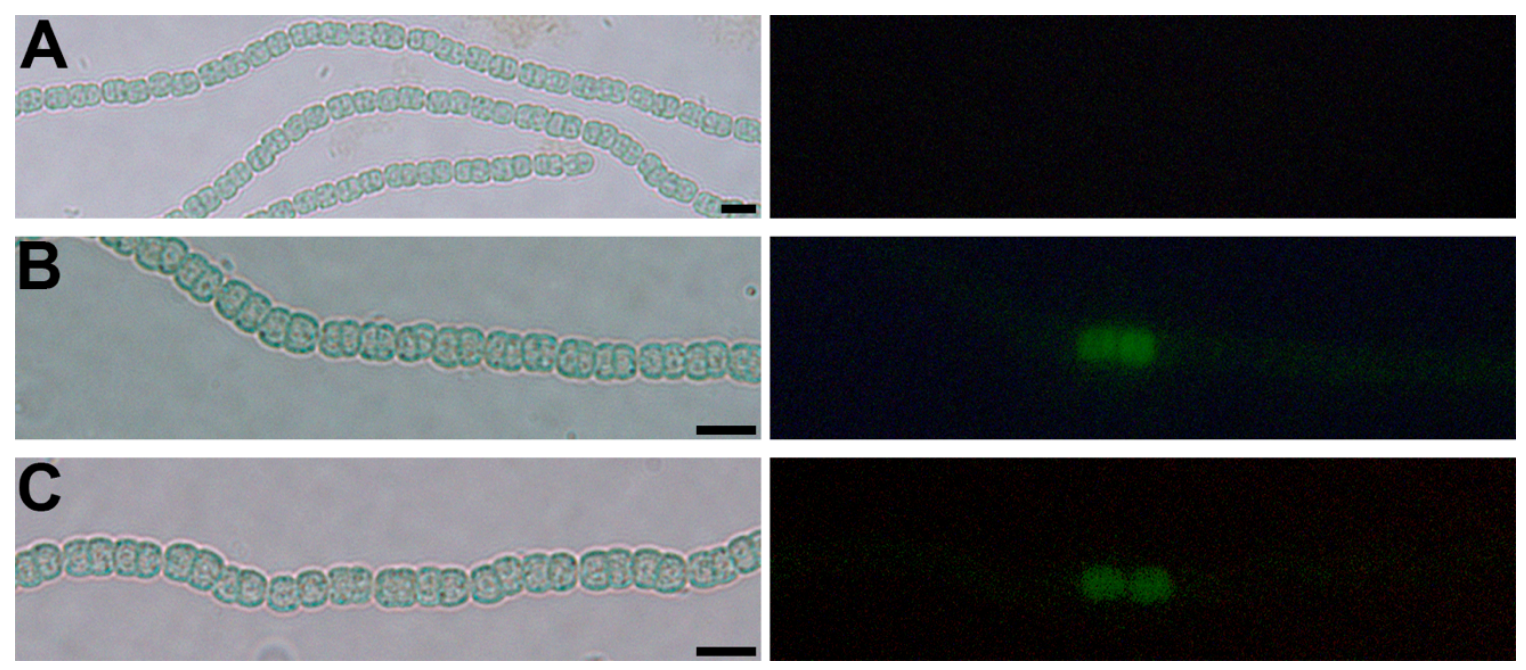

Supplementary Figure 10. The barA and jam $A$ promoters function in Anabaena 7120. Mosaic filaments of Anabaena 7120 were created with plasmids harboring a promoterless $g f p$ on $\mathrm{pAM} 1956(\mathrm{~A}), \mathrm{P}_{b a r A^{-}} g f p(\mathrm{~B})$, and $\mathrm{P}_{j a m A^{-}} g f p(\mathrm{C})$. The strain was cultured in BG-11 medium and representative brightfield (left) and green fluorescence from GFP (right) micrographs are presented from over 500 filaments observed. Bar, $10 \mu \mathrm{m}$. 
TAAACTCTAGGAAAAAAACATGGGGATTGACAAGGATAGTTAGCACTGATAACACTTGCACTGGAAATACT TTAGTAGGAGCAAGGGTGTATAAGGACACAGGTTCAAACCGATAAATTGCAATATAGCAATCCTCTAATCA GTTGTAATATTTGGTGGTAGTTAGGAGTCAGAATTCATAATTTTCAAGCTTTTCAGCTCAAATTAACTAT TATAAAAATTGTCACGACCAATGCGCGGATTGCTATATACATCTCCAGAAAAGAGGAAGTAGGGAGCAGGG AGCAGGGAGTAGGGAGAAATAATGATGATTTCTCTGGGATAATTGATTTTATTTTTTATTATTGGAGATG TCTAATG

Supplementary Figure 11. Intergenic region between ltxC and ltxD in Moorea producens. The predicted stop codon for $l t x C$ and start codon for $l t x D$ are shown as italicized bases at the 5'- and 3'-end of the sequence respectively. The underlined bases were identified as possible -35 (TTGATG) and -10 (TGGGATAAT) sequences by the BPROM program. ${ }^{3}$ The bold sequence was identified as a possible Shine-Dalgarno sequence by visual inspection. 


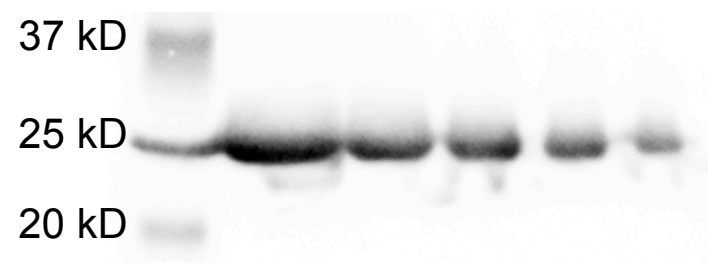

$15 \mathrm{kD}$

$\begin{array}{lllllllll}1 & 2 & 3 & 4 & 5 & 6 & 7 & 8 & 9\end{array}$

Supplementary Figure 12. LtxD-His $_{6}$ is produced in Anabaena 7120. Anabaena 7120 harboring an empty control plasmid pPJAV361 (Lane 7) or $\mathrm{P}_{l t x A}-l t x A$-C-LtxD-His 6 (Lanes 8 and 9) grown on BG-11 (Lanes 7 and 8 ) or BG-11( $\mathrm{NH}_{4}$ ) were subjected to a Western blot. LtxD-His 6 from Anabaena 7120 was compared to varying concentrations of purified recombinant $\mathrm{His}_{6}$-LtxD-His ${ }_{6}$ from E. coli $(500 \mathrm{ng}, 250 \mathrm{ng}, 125 \mathrm{ng}, 50 \mathrm{ng}, 25$ $\mathrm{ng}$ in lanes 2-6, respectively) and is present at about $25 \mathrm{kDa}$ compared to the Precision plus Prestained Protein ladder (Lane 1, expected mass is $28 \mathrm{kDa}$, Bio-Rad). 


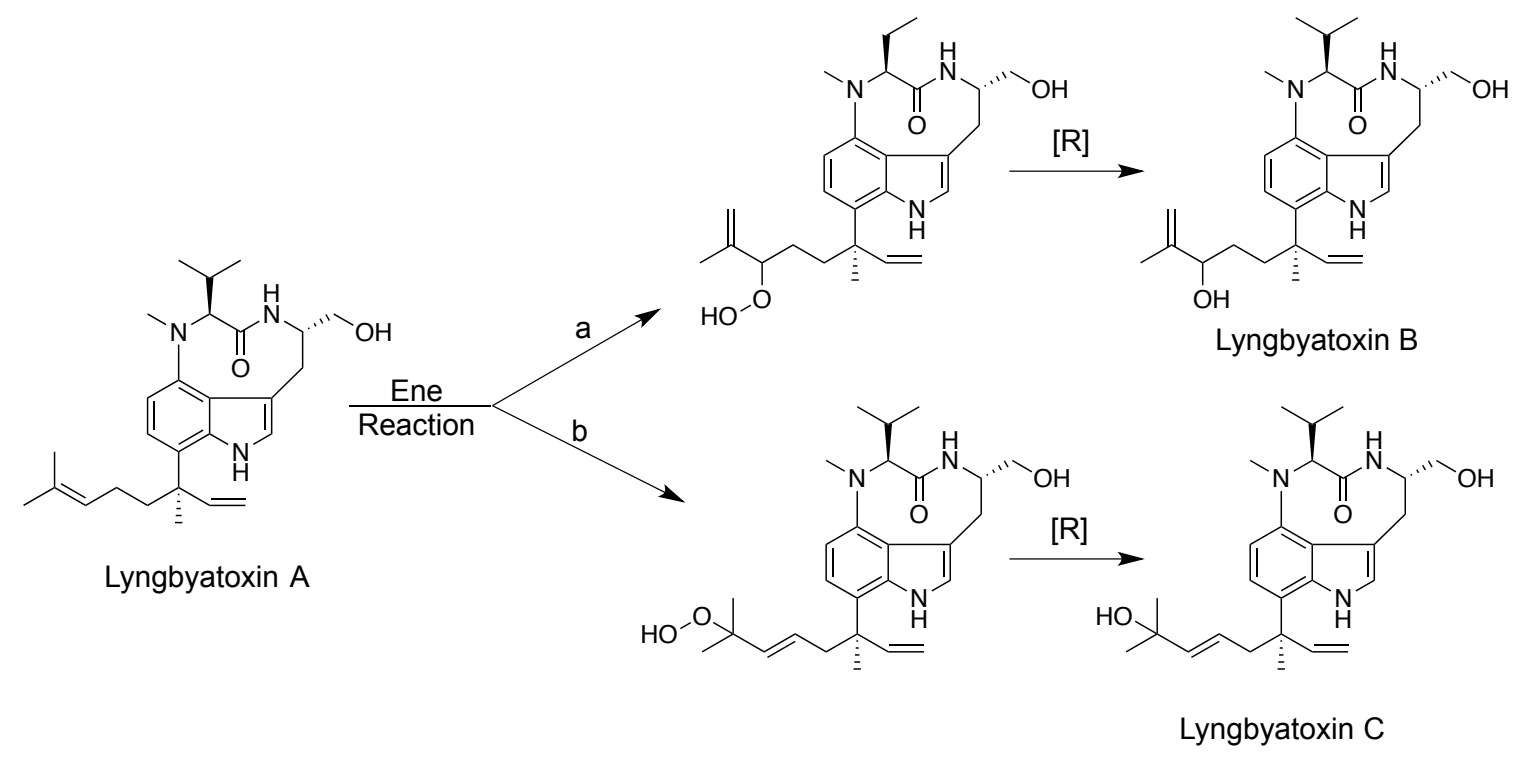

Supplementary Figure 13. Proposed conversion of lyngbyatoxin A to lyngbyatoxins B and $\mathrm{C}$. The ene reaction could be promoted by the chlorophyll inside the cyanobacterial cells, which would act as a sensitizer for molecular oxygen. Subsequent reduction of the resulting hydroperoxide yields lyngbyatoxin $\mathrm{B}$ or $\mathrm{C}$. 
Supplementary Table 1. ${ }^{1} \mathrm{H}$ NMR shifts of lyngbyatoxin $\mathrm{A}$ in $\mathrm{CDCl}_{3}$ (major conformer only). Lyngbyatoxin A numbering from reference 1, see Supplementary Figure 3.

\begin{tabular}{|c|c|c|}
\hline Position & $\begin{array}{c}{ }^{1} \text { H NMR } \\
\text { (this study) }\end{array}$ & $\begin{array}{c}{ }^{1} \mathrm{H} \text { NMR } \\
\text { (from reference 1) }\end{array}$ \\
\hline 1 & $8.50(\mathrm{~s}, \mathrm{br})$ & $8.50(\mathrm{~s}, \mathrm{br})$ \\
\hline 2 & $6.81(\mathrm{~s}, \mathrm{br})$ & $6.81(\mathrm{~s}, \mathrm{br})$ \\
\hline 5 & $6.48(\mathrm{~d}, 8 \mathrm{~Hz})$ & $6.44(\mathrm{~d}, 8 \mathrm{~Hz})$ \\
\hline 6 & $6.98(\mathrm{~d}, 8 \mathrm{~Hz})$ & $6.96(\mathrm{~d}, 8 \mathrm{~Hz})$ \\
\hline 8 & $3.08(-15.4,4.4 \mathrm{~Hz})$ & $3.11(\mathrm{dd},-17.5,2 \mathrm{~Hz})$ \\
\hline 9 & $4.31(\mathrm{~s}, \mathrm{br})$ & $4.32(\mathrm{~s}, \mathrm{br})$ \\
\hline 10 & $8.0(\mathrm{~s}, \mathrm{br})$ & $7.77(\mathrm{~s}, \mathrm{br})$ \\
\hline 12 & $4.33(10 \mathrm{~Hz})$ & $4.33(\mathrm{~d}, 12 \mathrm{~Hz})$ \\
\hline 15 & $\begin{array}{l}1.91(\mathrm{~m}) \\
1.84(\mathrm{~m})\end{array}$ & $\begin{array}{l}1.89(\mathrm{td},-12,3 \mathrm{~Hz}) \\
1.80(\mathrm{td},-12,3 \mathrm{~Hz})\end{array}$ \\
\hline 16 & $\begin{array}{l}1.94(\mathrm{~m}, \mathrm{br}) \\
1.71(\mathrm{~m}, \mathrm{br})\end{array}$ & $\begin{array}{l}1.93(\mathrm{~m}, \mathrm{br}) \\
1.70(\mathrm{~m}, \mathrm{br})\end{array}$ \\
\hline 17 & $5.07(\mathrm{~m}, \mathrm{br})$ & $5.06(\mathrm{~m}, \mathrm{br})$ \\
\hline 19 & $1.47(\mathrm{~s}, \mathrm{br})$ & $1.47(\mathrm{~s}, \mathrm{br})$ \\
\hline 20 & $1.63(\mathrm{~s}, \mathrm{br})$ & $1.63(\mathrm{~s}, \mathrm{br})$ \\
\hline 21 & $6.16(\mathrm{dd}, 17.6,10.6 \mathrm{~Hz})$ & $6.15(\mathrm{dd}, 18,10 \mathrm{~Hz})$ \\
\hline 22 & $\begin{array}{l}.38 \text { (unresolved, dd) } \\
5.33 \text { (unresolved dd) }\end{array}$ & $\begin{array}{l}5.30 \text { (unresolved dd, } 18 \mathrm{~Hz}) \\
5.26 \text { (unresolved dd, } 10 \mathrm{~Hz})\end{array}$ \\
\hline 23 & $1.45(\mathrm{~s})$ & $1.44(\mathrm{~s})$ \\
\hline 24 & $\begin{array}{c}3.74(\mathrm{dd},-11,4 \mathrm{~Hz}) \\
3.47 \text { (overlapping dd) }\end{array}$ & $\begin{array}{c}3.72(\mathrm{dd},-11.5,3 \mathrm{~Hz}) \\
3.56(\mathrm{dd},-11.5,8.5 \mathrm{~Hz})\end{array}$ \\
\hline 25 & $2.6(\mathrm{~m})$ & $2.55(\mathrm{~m})$ \\
\hline 26 & $0.92(\mathrm{~d}, 6 \mathrm{~Hz})$ & $0.89(\mathrm{~d}, 6.5 \mathrm{~Hz})$ \\
\hline 27 & $0.64(\mathrm{~d}, 6 \mathrm{~Hz})$ & $0.62(\mathrm{~d}, 6.5 \mathrm{~Hz})$ \\
\hline 28 & $2.91(\mathrm{~s})$ & $2.87(\mathrm{~s})$ \\
\hline
\end{tabular}


Supplementary Table 2. Lyngbyatoxin A production from replicative plasmid pPJAV500 containing the ltxA-C genes in Anabaena 7120. The strain was grown on plates containing either nitrate or ammonia as the sole nitrogen source. Plates were harvested in triplicate at the indicated times. The quantity of lyngbyatoxin A is presented as ng of compound per $\mathrm{mg}$ of dried cell mass \pm the standard deviation.

\begin{tabular}{|c|c|c|c|c|c|}
\hline Line & Nitrogen source & Week 1 & Week 2 & Week 3 & Week 4 \\
\hline 1 & Ammonia & $22.4 \pm 21.1$ & $126.4 \pm 27.5$ & $130.1 \pm 7$ & $60.8 \pm 24.3$ \\
\hline 2 & Nitrate & $2.6 \pm 1$ & $9.1 \pm 3.2$ & $18.4 \pm 2.3$ & $39.8 \pm 6.7$ \\
\hline
\end{tabular}

Supplementary Table 3. Cell mass in $\mathrm{mg}$ recovered from cultures utilized in Supplementary Table 2 for LTXA production from replicative plasmid pPJAV500 over time on solid BG-11 medium containing either ammonia or nitrate as the combined nitrogen source. Plates were harvested in triplicate at the indicated times, cultures were lyophilized, and the mass of each culture is presented as the average $\mathrm{mg} \pm$ the standard deviation.

\begin{tabular}{|c|c|c|c|c|c|}
\hline Line & Nitrogen Source & Week 1 & Week 2 & Week 3 & Week 4 \\
\hline 1 & Ammonia & $15.4 \pm 2.4$ & $32.5 \pm 1.7$ & $56.9 \pm 9.5$ & $59.6 \pm 4.5$ \\
\hline 2 & Nitrate & $5.0 \pm 1.4$ & $34.9 \pm 4.9$ & $77.8 \pm 8.6$ & $86.5 \pm 8.7$ \\
\hline
\end{tabular}

Supplementary Table 4. Analysis of the efficiency of extraction and quantification methods used to measure LTXA production. Cultures of Anabaena 7120 harboring pPJAV500 were grown on three BG-11(NH $\mathrm{NH}_{4}$ plates or BG-11 for three or four weeks, respectively. The three cultures were pooled such that a third of each culture was scraped into each of three vials, which were lyophilized and extracted as described in the materials and methods. The quantity of LTXA is presented as ng of compound per mg of dried cell mass.

\begin{tabular}{|c|c|c|c|c|c|c|}
\hline Line & $\begin{array}{c}\text { Nitrogen } \\
\text { Source }\end{array}$ & Plate 1 & Plate 2 & Plate 3 & $\begin{array}{c}\text { Average LTXA } \\
\text { Yield }\end{array}$ & $\begin{array}{c}\text { Standard } \\
\text { Deviation }\end{array}$ \\
\hline 1 & Ammonia & 190.9 & 188.5 & 189.3 & 189.6 & 1.2 \\
\hline 2 & Nitrate & 48.8 & 50.2 & 49.2 & 49.4 & 0.7 \\
\hline
\end{tabular}


Supplementary Table 5. Statistical analysis of LTXA production from Anabaena 7120 harboring different vectors with the ltx gene cluster controlled by native and heterologous promoters from Table 1. All LTXA production values from the individual conditions are compared to the yields from pPJAV500 harboring $\mathrm{P}_{l t x A}$-ltxA-C. Data from t-tests are presented as $p$-values. N/D not determined.

\begin{tabular}{|c|c|c|c|c|c|c|c|}
\hline Line & $\begin{array}{l}\text { Genes } \\
\text { Introduced }\end{array}$ & Plasmid & $\begin{array}{l}\text { Ammonia } \\
\text { Plates }^{2}\end{array}$ & $\begin{array}{l}\text { Nitrate } \\
\text { Plates }\end{array}$ & $\begin{array}{l}\text { Diazotrophy } \\
\text { Plates }^{c}\end{array}$ & $\begin{array}{l}\text { Ammonia } \\
\text { Liquid }^{c}\end{array}$ & $\begin{array}{l}\text { Nitrate } \\
\text { Liquid }^{d}\end{array}$ \\
\hline 1 & $\begin{array}{l}\mathrm{P}_{l t x A}-l t x A-C \\
\text { with Yeast } \\
\text { Element }\end{array}$ & pPJAV633 & 0.54 & 0.81 & $\mathrm{~N} / \mathrm{D}$ & N/D & N/D \\
\hline 2 & $\mathrm{P}_{\text {pet } E^{-}}-\operatorname{ltx} A-C$ & pPJAV501 & Not viable & $\begin{array}{c}1.7 \times \\
10^{-6}\end{array}$ & $7.6 \times 10^{-3}$ & 0.48 & 0.11 \\
\hline 3 & $\mathrm{P}_{\text {nirA }}-l t x A-C$ & pPJAV502 & 0.04 & 0.01 & $8.3 \times 10^{-5}$ & $3.9 \times 10^{-3}$ & 0.12 \\
\hline 4 & $\mathrm{P}_{g l n A}-\operatorname{lt} x A-C$ & pPJAV503 & 0.01 & $\begin{array}{c}1.8 \times \\
10^{-5} \\
\end{array}$ & $1.5 \times 10^{-3}$ & $2.7 \times 10^{-4}$ & 0.01 \\
\hline 5 & $\mathrm{P}_{l t x A}-l t x A-D$ & pPJAV571 & 0.09 & 0.07 & 0.27 & 0.06 & 0.07 \\
\hline
\end{tabular}

Supplementary Table 6. Cell mass in mg recovered from cultures utilized in Table 1 for lyngbyatoxin A production from replicative plasmids containing the $\operatorname{lt} x A-C$ or $\operatorname{lt} x A-D$ genes expressed from the native or heterologous promoters in Anabaena 7120. Cultures were harvested in triplicate at the indicated times, lyophilized, and the mass of each culture is presented as the average $\mathrm{mg} \pm$ the standard deviation. N/D, not determined.

\begin{tabular}{|c|c|c|c|c|c|c|c|}
\hline Line & $\begin{array}{l}\text { Genes } \\
\text { Introduced }\end{array}$ & Plasmid & $\begin{array}{l}\text { Ammonia } \\
\text { Plates }^{\text {a }}\end{array}$ & $\begin{array}{l}\text { Nitrate } \\
\text { Plates }^{\text {b }}\end{array}$ & $\begin{array}{l}\text { Diazotrophy } \\
\text { Plates }^{\text {c }}\end{array}$ & $\begin{array}{l}\text { Ammonia } \\
\text { Liquid }^{c}\end{array}$ & $\begin{array}{l}\text { Nitrate } \\
\text { Liquid }^{d}\end{array}$ \\
\hline 1 & $\begin{array}{l}\text { Empty } \\
\text { vector }\end{array}$ & pPJAV361 & $54.2 \pm 1.5$ & $\begin{array}{l}80.6 \pm \\
14.1\end{array}$ & $17.7 \pm 2.3$ & $12.8 \pm 3.1$ & $\begin{array}{l}34.3 \pm \\
4.3\end{array}$ \\
\hline 2 & $\mathrm{P}_{l t x A^{-}}-\operatorname{ltx} A-C$ & pPJAV500 & $50.3 \pm 7.4$ & $\begin{array}{l}98.0 \pm \\
8.2\end{array}$ & $13.9 \pm 0.8$ & $2.3 \pm 1.1$ & $\begin{array}{l}27.5 \pm \\
1.5\end{array}$ \\
\hline 3 & $\begin{array}{l}\mathrm{P}_{l t x A}-l t x A-C \\
\text { with Yeast } \\
\text { Element }\end{array}$ & pPJAV633 & $47.4 \pm 7.8$ & $\begin{array}{l}94.1 \pm \\
9.3\end{array}$ & $\mathrm{~N} / \mathrm{D}$ & $\mathrm{N} / \mathrm{D}$ & $\mathrm{N} / \mathrm{D}$ \\
\hline 4 & $\mathrm{P}_{\text {petE }}-l t x A-C$ & pPJAV501 & Not viable & $\begin{array}{l}92.7 \pm \\
3.9\end{array}$ & $13.9 \pm 1.9$ & $2.3 \pm 1.0$ & $\begin{array}{l}25.1 \pm \\
5.5\end{array}$ \\
\hline 5 & $\mathrm{P}_{\text {nirA }}-l t x A-C$ & pPJAV502 & $56.1 \pm 3.5$ & $\begin{array}{l}93.4 \pm \\
17.2 \\
\end{array}$ & $16.0 \pm 2.1$ & $4.5 \pm 0.2$ & $\begin{array}{l}26.9 \pm \\
6.1 \\
\end{array}$ \\
\hline 6 & $\mathrm{P}_{g l n}-l t x A-C$ & pPJAV503 & $17.2 \pm 1.6$ & $\begin{array}{l}56.5 \pm \\
9.7\end{array}$ & $18.0 \pm 2.4$ & $1.7 \pm 0.2$ & $\begin{array}{l}20.3 \pm \\
0.2\end{array}$ \\
\hline 7 & $\mathrm{P}_{l t x A^{-}}-l t x A-D$ & pPJAV571 & $47.8 \pm 8.5$ & $\begin{array}{l}78.8 \pm \\
15.2\end{array}$ & $19.2 \pm 2.8$ & $1.9 \pm 0.1$ & $\begin{array}{l}28.8 \pm \\
4.4\end{array}$ \\
\hline
\end{tabular}


Supplementary Table 7. Statistical analysis of cell mass in $\mathrm{mg}$ recovered from Anabaena 7120 cultures harboring different vectors with the ltx gene cluster controlled by native and heterologous promoters from Supplemental Table 6. All cell mass values from the individual conditions are compared to the yields from the empty vector control plasmid pPJAV361. Data from t-tests are presented as $p$-values. N/D, not determined.

\begin{tabular}{|c|c|c|c|c|c|c|c|}
\hline Line & $\begin{array}{l}\text { Genes } \\
\text { Introduced }\end{array}$ & Plasmid & $\begin{array}{l}\text { Ammonia } \\
\text { Plates }^{\text {a }}\end{array}$ & $\begin{array}{l}\text { Nitrate } \\
\text { Plates }^{b}\end{array}$ & $\begin{array}{l}\text { Diazotrophy } \\
\text { Plates }^{c}\end{array}$ & $\begin{array}{l}\text { Ammonia } \\
\text { Liquid }^{c}\end{array}$ & $\begin{array}{l}\text { Nitrate } \\
\text { Liquid }^{d}\end{array}$ \\
\hline 1 & $\mathrm{P}_{l t x A^{-}} l t x A-C$ & pPJAV500 & 0.42 & 0.08 & 0.06 & $4.6 \times 10^{-3}$ & 0.07 \\
\hline 2 & $\begin{array}{l}\mathrm{P}_{\text {ltxA }}-\text { ltx } A-C \\
\text { with Yeast } \\
\text { Element }\end{array}$ & pPJAV633 & 0.24 & 0.44 & $\mathrm{~N} / \mathrm{D}$ & $\mathrm{N} / \mathrm{D}$ & $\mathrm{N} / \mathrm{D}$ \\
\hline 3 & $\mathrm{P}_{p e t E^{-}}-l t x A-C$ & pPJAV501 & Not viable & 0.45 & 0.09 & $4.2 \times 10^{-3}$ & 0.08 \\
\hline 4 & $\mathrm{P}_{\text {nirA }}-l t x A-C$ & pPJAV502 & 0.43 & 0.58 & 0.39 & $8.1 \times 10^{-3}$ & 0.15 \\
\hline 5 & $\mathrm{P}_{g \ln A}-\operatorname{lt} x A-C$ & pPJAV503 & $7.7 \times 10^{-6}$ & 0.04 & 0.89 & $2.9 \times 10^{-3}$ & $\begin{array}{c}6.8 \times \\
10^{-3}\end{array}$ \\
\hline 6 & $\mathrm{P}_{l t x A}-l t x A-D$ & pPJAV571 & 0.28 & 0.24 & 0.51 & $2.2 \times 10^{-3}$ & 0.23 \\
\hline
\end{tabular}


Supplementary Table 8. Statistical analysis of the correlations between promoter strength, gene expression, and LTXA production. Values used to present the relative strength of each promoter by CAT assay from Table 2 (CAT), ltx $A-C$ expression from the specified primer set from Figure 4 (RNA), and LTXA yields from Table 1 (LTXA) were assessed for correlation by calculating Pearson's $r$ and the $p$-value for each interaction. Positive $r$ values denote a positive correlation and $p<0.05$ was defined as a significant correlation.

\begin{tabular}{|c|c|c|c|c|c|c|c|c|c|}
\hline \multirow[t]{2}{*}{ Line } & \multirow[t]{2}{*}{$\begin{array}{c}\text { Correlation } \\
\text { assessed }\end{array}$} & \multicolumn{2}{|c|}{$\begin{array}{c}\text { Ammonia } \\
\text { Plates }\end{array}$} & \multicolumn{2}{|c|}{ Nitrate Plates } & \multicolumn{2}{|c|}{$\begin{array}{c}\text { Ammonia } \\
\text { Liquid }\end{array}$} & \multicolumn{2}{|c|}{ Nitrate Liquid } \\
\hline & & $r$ & $p$ & $r$ & $p$ & $r$ & $p$ & $r$ & $p$ \\
\hline 1 & LTXA and CAT & 0.88 & $7 \times 10^{-3}$ & 0.86 & $3 \times 10^{-4}$ & 0.84 & $6 \times 10^{-4}$ & 0.61 & 0.03 \\
\hline & & \multicolumn{8}{|c|}{ ltx $A \mathrm{~N}$-terminus (ltxA1 primer pair) } \\
\hline 2 & CAT and RNA & 0.91 & $1 \times 10^{-3}$ & 0.20 & 0.54 & 0.90 & $7 \times 10^{-5}$ & 0.93 & $1 \times 10^{-5}$ \\
\hline 3 & LTXA and RNA & 0.95 & $1 \times 10^{-4}$ & 0.65 & 0.02 & 0.92 & $3 \times 10^{-5}$ & 0.74 & $4 \times 10^{-3}$ \\
\hline & & \multicolumn{8}{|c|}{ ltxA $\mathrm{C}$-terminus (ltxA4 primer pair) } \\
\hline 4 & CAT and RNA & 0.81 & $7 \times 10^{-3}$ & 0.34 & 0.28 & 0.76 & $4 \times 10^{-3}$ & 0.63 & 0.03 \\
\hline 5 & LTXA and RNA & 0.48 & 0.19 & 0.49 & 0.10 & 0.89 & $1 \times 10^{-4}$ & -0.15 & 0.64 \\
\hline & & \multicolumn{8}{|c|}{ ltxB (ltxB primer pair) } \\
\hline 6 & CAT and RNA & 0.79 & 0.01 & 0.41 & 0.19 & 0.96 & $1 \times 10^{-5}$ & 0.60 & 0.04 \\
\hline 7 & LTXA and RNA & 0.91 & $6 \times 10^{-4}$ & 0.56 & 0.05 & 0.92 & $2 \times 10^{-5}$ & -0.19 & 0.56 \\
\hline & & \multicolumn{8}{|c|}{ ltx $C$ (ltxC primer pair) } \\
\hline 8 & CAT and RNA & -0.46 & 0.21 & 0.24 & 0.44 & -0.60 & 0.04 & -0.97 & $1 \times 10^{-5}$ \\
\hline 9 & LTXA and RNA & -0.08 & 0.85 & -0.17 & 0.59 & -0.18 & 0.58 & -0.61 & 0.03 \\
\hline
\end{tabular}

Supplementary Table 9. Cell mass in mg recovered from cultures utilized in Figure 3 to examine the effect of nitrogen limitation on LTXA production and accumulation. The Anabaena strain containing pPJAV500 was grown in liquid cultures containing nitrate or ammonia as the sole nitrogen source for two weeks or eight days, respectively, in triplicate. Halfway through the experimental duration, three cultures were washed and fresh medium containing the same nitrogen source was added, three cultures were stepped down to medium lacking a combined nitrogen source (diazotrophic), and three cultures left growing unaltered. At the conclusion of the growth period, the cultures were individually filtered, lyophilized, and the mass of each culture is presented as the average $\mathrm{mg} \pm$ the standard deviation.

\begin{tabular}{|c|c|c|c|c|}
\hline Line & Growth Conditions & $\begin{array}{c}\text { Combined } \\
\text { Nitrogen }\end{array}$ & $\begin{array}{c}\text { Combined } \\
\text { Nitrogen Replaced }\end{array}$ & Diazotrophic \\
\hline 1 & Nitrate & $20.4 \pm 4.7$ & $35.8 \pm 4.9$ & $19.1 \pm 6.3$ \\
\hline 2 & Ammonia & $2.4 \pm 1.1$ & $1.9 \pm 0.4$ & $2.6 \pm 0.4$ \\
\hline
\end{tabular}


Supplementary Table 10. Statistical analysis of LTXA production from Anabaena 7120 harboring pPJAV500 from Figure 3. All LTXA production values from the individual conditions are compared to the yields from Anabaena 7120 harboring pPJAV500 in the unmodified growth condition (either nitrate or ammonia growth). Data from t-tests are presented as $p$-values.

\begin{tabular}{|c|c|c|c|}
\hline Line & $\begin{array}{c}\text { Growth Condition for } \\
\text { Comparison }\end{array}$ & $\begin{array}{c}\text { Combined Nitrogen } \\
\text { Replaced }\end{array}$ & Diazotrophic \\
\hline 1 & Nitrate & 0.04 & $8.8 \times 10^{-3}$ \\
\hline 2 & Ammonia & 0.89 & 0.46 \\
\hline
\end{tabular}

Supplementary Table 11. Statistical analysis to compare production of LTXA from Supplementary Table 1 to that from Table 1 following three weeks of growth on ammonia plates or four weeks on nitrate plates from Anabaena 7120 harboring $\mathrm{P}_{l t x A}-$ ltxA $C$ on either pPJAV500 or pPJAV633. All LTXA production values from the individual conditions are compared to the yields from pPJAV500 harboring $\mathrm{P}_{l t x A}-l t x A-C$ from Supplementary Table 2. Data from t-tests are presented as $p$-values.

\begin{tabular}{|c|c|c|c|c|}
\hline Line & Genes Introduced & Plasmid & Ammonia & Nitrate \\
\hline 1 & $\mathrm{P}_{l t x A^{-}-l t x A-C}$ & pPJAV500 & 0.33 & 0.97 \\
\hline 2 & $\begin{array}{c}\mathrm{P}_{l t x A^{-}-l t x A-C \text { with }} \\
\text { Yeast Element }\end{array}$ & pPJAV633 & 0.36 & 0.82 \\
\hline
\end{tabular}


Supplementary Table 12. Proteins identified by BLASTP analysis of the non-redundant protein database using LtxD as a query.

\begin{tabular}{|c|c|c|c|}
\hline Locus tag & Species & \% Identity & Accession number \\
\hline IH17_RS0109225 & $\begin{array}{l}\text { Streptomyces sp. } \\
\text { NRRL F-5527 }\end{array}$ & 60 & WP_031061495 \\
\hline H114_13441 & $\begin{array}{l}\text { Streptomyces } \\
\text { gancidicus BKS 13-15 }\end{array}$ & 60 & WP_039987293 \\
\hline B100_RS0123795 & $\begin{array}{l}\text { Streptomyces sp. } \\
\text { CNH189 }\end{array}$ & 59 & WP_037723345 \\
\hline IF98_RS0111195 & $\begin{array}{l}\text { Streptomyces sp. } \\
\text { NRRL S-1314 }\end{array}$ & 59 & WP_031018979 \\
\hline WN71_RS07695 & $\begin{array}{l}\text { Streptomyces sp. } \\
\text { MUSC149T }\end{array}$ & 56 & WP_046583800 \\
\hline SCO7266 & $\begin{array}{l}\text { Streptomyces } \\
\text { coelicolor A3(2) }\end{array}$ & 56 & CAB42951 \\
\hline ADY01_RS05565 & $\begin{array}{l}\text { Streptomyces sp. } \\
\text { SBT349 }\end{array}$ & 58 & WP_049566489 \\
\hline BS72_RS23155 & $\begin{array}{l}\text { Streptomyces } \\
\text { yeochonensis CN732 }\end{array}$ & 55 & WP_037913219 \\
\hline TR66_09625 & $\begin{array}{l}\text { Streptomyces sp. } \\
\text { WM6391 }\end{array}$ & 57 & KKD15616 \\
\hline IF14_RS0115620 & $\begin{array}{l}\text { Streptomyces } \\
\text { violaceoruber NRRL } \\
\text { S-12 }\end{array}$ & 57 & WP_030866843 \\
\hline
\end{tabular}


Supplementary Table 13. Strains and plasmids utilized in this study.

\begin{tabular}{|c|c|c|}
\hline Strain or plasmid & Characteristic(s)* & Source or reference \\
\hline \multicolumn{3}{|l|}{ Anabaena sp. } \\
\hline PCC 7120 & Wild type & $\begin{array}{l}\text { Pasteur Culture } \\
\text { Collection }\end{array}$ \\
\hline BJP001 & $\begin{array}{l}\mathrm{P}_{l t x A}-l t x A-C \text { integrated as a single recombinant } \\
\text { into the intergenic region between alr } 2328 \text { and } \\
\text { asl } 2329\end{array}$ & This study \\
\hline \multicolumn{3}{|l|}{ E. coli } \\
\hline BL21(DE3)-T1 ${ }^{\mathrm{R}}$ & Protein expression strain resistant to $\mathrm{T} 1$ phage & $\begin{array}{l}\text { New England } \\
\text { Biolabs }\end{array}$ \\
\hline BW25113 & Strain for lambda red recombination & 44 \\
\hline \multicolumn{3}{|l|}{ Yeast } \\
\hline VL6-48N & $\begin{array}{l}\text { Histidine auxotrophic strain for transformation- } \\
\text { assisted recombination (TAR) } \\
(M A T \alpha, \text { his } 3-\Delta 200 \text {, trp } 1-\Delta 1, \text { ura3- } \Delta 1, \text { lys } 2 \text {, ade2- } \\
\left.\text { 101, met14, cir }{ }^{0}\right)\end{array}$ & 5 \\
\hline \multicolumn{3}{|l|}{ Plasmids } \\
\hline pBlueScript SK+ & Cloning vector, $\mathrm{Ap}^{\mathrm{r}}$ & Stratagene \\
\hline pET28a & $\begin{array}{l}\text { Expression vector for creating histidine-tagged } \\
\text { proteins; } \mathrm{Km}^{\mathrm{r}}\end{array}$ & EMD Millipore \\
\hline pACYC184 & E. coli cloning vector, $\mathrm{Cm}^{\mathrm{r}} \mathrm{Tet}^{\mathrm{r}}$ & 6 \\
\hline pAM504 & $\begin{array}{l}\text { Shuttle vector for replication in E. coli and } \\
\text { Anabaena } ; \mathrm{Km}^{\mathrm{r}} \mathrm{Nm}^{\mathrm{r}}\end{array}$ & 7 \\
\hline pAM1956 & pAM504 with promoterless $g f p$ & 8 \\
\hline pDW9 & Source of $\mathrm{Sp}^{\mathrm{r}} / \mathrm{Sm}^{\mathrm{r}} \Omega$ interposon & 9 \\
\hline fos-DE3-86 & $\begin{array}{l}\text { Fosmid containing ltxA-D from Moorea } \\
\text { producens; } \mathrm{Cm}^{\mathrm{r}}\end{array}$ & 10 \\
\hline pKD46 & 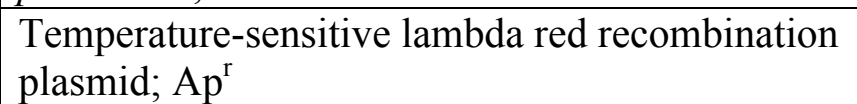 & 11 \\
\hline pPJAV123 & pAM504 lacking the $\mathrm{NdeI}$ site & 12 \\
\hline pRL277 & Suicide vector; $\mathrm{Sp}^{\mathrm{r}} / \mathrm{Sm}^{\mathrm{r}}$ & 13 \\
\hline pET28a-ltxD-1 & $\begin{array}{l}\text { Expression vector for purifying C-terminal } \\
\text { polyhistidine epitope-tagged LtxD }\end{array}$ & This study \\
\hline pUC57-P ${ }_{b a r A}$ & Source of barA promoter; $\mathrm{Ap}^{\mathrm{r}}$ & This study \\
\hline pUC57-P $\mathrm{P}_{\text {cur }}$ & Source of curA promoter; $A p^{r}$ & This study \\
\hline pUC57-P jamA & Source of jamA promoter; $A p^{r}$ & This study \\
\hline pUC57-P & Source of patA promoter; $\mathrm{Ap}^{\mathrm{r}}$ & This study \\
\hline pPJAV361 & $\begin{array}{l}\text { pAM504 with } \mathrm{Sp}^{\mathrm{r}} / \mathrm{Sm}^{\mathrm{r}} \Omega \text { interposon replacing } \\
\text { nptII }\end{array}$ & This study \\
\hline pPJAV500 & pPJAV361 with $\mathrm{P}_{l t x A}-l t x A-C$ & This study \\
\hline pPJAV501 & pPJAV361 with $\mathrm{P}_{\text {petE- }}-l t x A-C$ & This study \\
\hline
\end{tabular}




\begin{tabular}{|c|c|c|}
\hline pPJAV502 & pPJAV361 with $\mathrm{P}_{\text {PnirA }}$-ltxA-C & This study \\
\hline pPJAV503 & pPJAV361 with $\mathrm{P}_{g l n A}-l t x A-C$ & This study \\
\hline pPJAV508 & pAM504 with $\mathrm{P}_{l t \times A^{-}}-g f p$ & This study \\
\hline pPJAV536 & pAM504 with $\mathrm{P}_{l t x D}-g f p$ & This study \\
\hline pPJAV537 & pAM504 with $\mathrm{P}_{\text {bart }}-g f p$ & This study \\
\hline pPJAV538 & pAM504 with $\mathrm{P}_{\text {curt }}-g f p$ & This study \\
\hline pPJAV539 & pAM504 with $\mathrm{P}_{j a m A}-g f p$ & This study \\
\hline pPJAV540 & pAM504 with $\mathrm{P}_{\text {patA }}-g f p$ & This study \\
\hline pPJAV550 & $\begin{array}{l}\text { pPJAV361 with the yeast element for TAR } \\
\text { cloning }\end{array}$ & This study \\
\hline pPJAV560 & pPJAV361 with $\mathrm{P}_{\text {cat }}$-cat & This study \\
\hline pPJAV561 & pPJAV361 with promoterless cat & This study \\
\hline pPJAV562 & pPJAV361 with $\mathrm{P}_{l t x A^{-}}-c a t$ & This study \\
\hline pPJAV568 & $\begin{array}{l}\text { pPJAV550 with } \mathrm{P}_{l t x A}-l t x A-C \text { cloned with lambda } \\
\text { red recombination }\end{array}$ & This study \\
\hline pPJAV571 & $\begin{array}{l}\text { pPJAV550 with } \mathrm{P}_{l t x A}-l t x A-D \text { cloned with lambda } \\
\text { red recombination }\end{array}$ & This study \\
\hline pPJAV574 & pPJAV361 with $\mathrm{P}_{l t x D^{-}}-c a t$ & This study \\
\hline pPJAV575 & pPJAV361 with $\mathrm{P}_{b a r A^{-}-c a t}$ & This study \\
\hline pPJAV576 & pPJAV361 with $\mathrm{P}_{\text {curA }}{ }^{-c a t}$ & This study \\
\hline pPJAV577 & pPJAV361 with $\mathrm{P}_{j a m A^{-}}-c a t$ & This study \\
\hline pPJAV578 & pPJAV361 with $\mathrm{P}_{\text {patA }}-c a t$ & This study \\
\hline pPJAV608 & pPJAV361 with $\mathrm{P}_{\text {petE- }}-c a t$ & This study \\
\hline pPJAV609 & pPJAV361 with $\mathrm{P}_{\text {nirA }}-c a t$ & This study \\
\hline pPJAV610 & pPJAV361 with $\mathrm{P}_{g l n A^{-}}-c a t$ & This study \\
\hline pPJAV612 & pPJAV550 with $\mathrm{P}_{l t x A}-l t x A-D$-His 6 & This study \\
\hline pPJAV633 & pPJAV550 with $\mathrm{P}_{l t x A}-l t x A-C$ cloned with TAR & This study \\
\hline pPJAV654 & $\begin{array}{l}\text { pPJAV550 with the entire } M \text {. producens portion } \\
\text { of fos-DE3-86 cloned with lambda red } \\
\text { recombination }\end{array}$ & This study \\
\hline
\end{tabular}

* Km, kanamycin; Nm, neomycin; Sp, spectinomycin; Sm, streptomycin; Ap, ampicillin; $\mathrm{Cm}$, chloramphenicol; Tet, tetracycline 
Supplementary Table 14. Oligonucleotide primers used in this study. Underlined bases indicate restriction enzyme recognition sequences, while italicized bases indicate additional random bases added to increase restriction enzyme efficiency.

\begin{tabular}{|l|l|}
\hline Primer Name & Sequence (5' to 3') \\
\hline BD16SF1 & CACACTGGGACTGAGACAC \\
\hline BD16SR1 & CTGCTGGCACGGAGTTAG \\
\hline CAT-SacI-R & TATATGAGCTCTTACGCCCCGCCCTGCCACTCATCG \\
\hline CAT-SmaI-F & $\begin{array}{l}\text { ATCCCGGGAGGAGGAAAGCTAAAATGGAGAAAAAAATCACTG } \\
\text { GATATACCACC }\end{array}$ \\
\hline fos-up-F & GGCTGCATCCGATGCAAGTGTGTCGCTG \\
\hline fos-up-BamHI-R & $\begin{array}{l}\text { ATATAGGATCCTTCGTATAATGTATGCTATACGAAGTTATTAG } \\
\text { CG }\end{array}$ \\
\hline fos-dn-BamHI-F & ATATAGGATCCGGTGTAACAAGGGTGAACACTATCCCATATC \\
\hline fos-dn-EcoRI-R & TATATGAATTCGAGCTTATCGCGAATAAATACCTGTGACGG \\
\hline glnA-dn-out-R & GGAGGCGTTCCTACATTCGC \\
\hline glnA-up-out-F & CACCACGAAGTTGCTACTG \\
\hline glnANS-dn-F & GTCTTCTGTCCCGGGAAAAATTATGTATAAGTATACTAGAGG \\
\hline glnANS-dn-R & GACCAACAAATCAGTTAGCCACATGGCATGACG \\
\hline glnANS-up-BamHI-F & ATATAGGATCCGTGCGAGCTAGGCTTCCGCTTTGGTAAG \\
\hline glnANS-up-R & AATTTTCCCGGGACAGAAGACAAAAAACCACCCATAAG \\
\hline ltxA-int-SmaI-R & ATATACCCGGGTGACATATGTGGTGGTCTCTGTAG \\
\hline ltxA-PglnA-OEX-F & $\begin{array}{l}\text { GGCAGAGAAGGAGTAACAATGATTATGAATCAACCTTGGAGT } \\
\text { GGAAGTAGGCGGGC }\end{array}$ \\
\hline ltxA-Pnir-OEX-F & CTTTATGAGAACCAGCTCATGATTATGAATCAACCTTGGAGTG \\
GAAGTAGGCGGGC \\
\hline ltxA-PpetE-OEX-F & $\begin{array}{l}\text { ACAGGTTAGGAGAACGCCATGATTATGAATCAACCTTGGAGT } \\
\text { GGAAGTAGGCGGGC }\end{array}$ \\
\hline ItxA-RNA-F1 & ATGATTATGAATCAACCTTG \\
\hline ltxA-RNA-R1 & CAGCAACCACTAACTCAATC \\
\hline ltxA-RNA-F4 & CAATTAGAACAGTACGTCGA \\
\hline ltxA-RNA-R4 & TTACTTTCCTGTATAAGTTATTTG \\
\hline ltxB-RNA-F & ATGACAAATCCTTTTGCA \\
\hline ltxB-RNA-R & CCATGTTAAGGGCAACATAT \\
\hline ltxC-RNA-F & ATGAATTCAAAGATCGCTG \\
\hline ltxC-RNA-R & TACAGAGTTTACGAAGGAAGG \\
\hline ltxC-dn-ScaI-F & TGGAGTGGAGTACTCCAGCAGAGCGTAGGGATACCATAG \\
\hline ltxC-R & TTATGACCGTTTATAGACTCCTGGTGCAAG \\
\hline ltxC-up-ScaI-R & CTGCTGGAGTACTCCACTCCAAGGTTGATTCATAATCATAG \\
\hline ltxD-dn-ScaI-F & GGAGTGGAGTACTAGTAGGAGCAAGGGTGTATAAGGACAC \\
\hline ltxD-R & TTAGATCAACCCTCCTGTAACTCTCAAATTTTGTCCTG \\
\hline ltxD-up-ScaI-R & TCCTACTAGTACTCCACTCCAAGGTTGATTCATAATCATAGGG \\
\hline ltxDfwd & ATCTGATCGACATATGGGAAAACTACAAGGTAAGGTTGCTATT \\
\hline ltxDrev & TAGATCTAGCTCGAGGATCAACCCTCCTGTAACTCTCAAATTTT \\
\hline PbarA-F & GAGTATAGTCCTGATTATAACTTAATTGAATTGG \\
\hline PbarA-R & \\
\hline
\end{tabular}




\begin{tabular}{|l|l|}
\hline Pcat-F & GCCGCGGCCCTCTCACTTCCCTG \\
\hline PcurA-F & TACGCTGGCGTAATTGCAGTGCCC \\
\hline PcurA-R & TTTTTGATATTTATTGGTTTTACTCTGAATAGGATGTTAG \\
\hline pETseq- & GGTTATGCTAGTTATTGCTCAGCGG \\
\hline PglnA-OEX-R & TGTTACTCCTTCTCTGCCAATTCTTAAATTCAAACCAG \\
\hline PglnA-XhoI-F & ATATACTCGAGCGCAGATAGTAGTCCATATCTCGTAAAC \\
\hline PjamA-F & AGGATGAAAGTACCTTAATCAATGGATTGC \\
\hline PjamA-R & ATATCAAATAAATATACATTTCCCATCAGTCCC \\
\hline Pltx-R & AGGGGGATAATTTAATCTAGCCCTC \\
\hline PltxA-XhoI-F & ATATACTCGAGTTCACCTTCTGTCTAGAATTACAGTTTGAGG \\
\hline PltxD-F & CAGGTATTGCTTGGTTATCTGACAGACC \\
\hline PltxD-R & TAGACATCTCCAATAATAAAAAATAAAATCAATTATCCCAGA \\
\hline G & \\
\hline Pnir-OEX-R & GAGCTGGTTCTCATAAAGTTTTTTTGCTCAAGATCAATCCACC \\
\hline Pnir-XhoI-F & ATATACTCGAGAGCTACTCATTAGTTAAGTGTAATGCAG \\
\hline PpatA-F & TTCGTGAAAATTGCTCTTTGAATAAAGGG \\
\hline PpatA-R & GGTGATAGACGAGTATTTTTGCTATAGG \\
\hline PpetE-OEX-R & GGCGTTCTCCTAACCTGTAGTTTTATTTTC \\
\hline PpetE-XhoI-F & TATATCTCGAGGCTGAGGTACTGAGTACACAGC \\
\hline YE-SacI-F & $\begin{array}{l}\text { ATATAGAGCTCTGTATTTAGAAAAATAAACAAATAGGGGTTCC } \\
\text { GCGCAC }\end{array}$ \\
\hline YE-SmaI-R & ATATACCCGGGTAAACTTGGTCTGACAGTTAGGTTCACGTAGTG \\
\hline
\end{tabular}




\section{Experimental Section}

General methods. LCMS grade water and methanol, and the pET28a vector were purchased from EMD Millipore (Billerica, MA), while all restriction enzymes, Escherichia coli NEB10 $\beta$ cells, E. coli BL21(DE3)-T1 ${ }^{\mathrm{R}}$ cells, and T4 DNA ligase were purchased from New England Biolabs (Ipswich, MA). The QIAquick PCR purification kit, QIAquick gel extraction kit, and QIAprep Spin Miniprep Kit were purchased from Qiagen (Valencia, CA) and were used according to the manufacturer's instructions. LCMS grade acetonitrile and formic acid were purchased from Fisher Chemicals (Pittsburgh, PA). Chloramphenicol acetyltransferase and all other chemicals were purchased from Sigma-Aldrich (St. Louis, MO) and used without further purification unless otherwise specified. Sanger sequencing was performed with Big Dye Terminator chemistry at the Center for Genome Resources and Biocomputing (Oregon State University). All UV-vis spectroscopy was performed using a BioSpectrometer kinetic (Eppendorf, Hauppauge, NY). Primerstar GXL, SD medium, and Dropout supplement (Trp-) were purchased from CloneTech and used according to the manufacturer's instructions.

Bacterial strains and growth conditions. E. coli was routinely cultured in Lysogeny Broth, Miller (LB) broth for liquid culture and on LB solidified with $1.5 \%$ agar for plate culture. Media were supplemented with spectinomycin, kanamycin, ampicillin, or chloramphenicol at a concentration of $100 \mu \mathrm{g} \mathrm{mL}^{-1}, 50 \mu \mathrm{g} \mathrm{mL} \mathrm{m}^{-1}, 100 \mu \mathrm{g} \mathrm{mL} \mathrm{m}^{-1}$, or $15 \mu \mathrm{g}$ $\mathrm{mL}^{-1}$, respectively, for plasmid selection in E. coli. Anabaena sp. strain PCC 7120 (Anabaena 7120) was routinely grown on BG-11 medium as previously described ${ }^{14,15}$ at $28^{\circ} \mathrm{C}$ with an $18 \mathrm{~h}-6 \mathrm{~h}$ light-dark cycle of cool white fluorescent light at an average intensity of 25 microeinsteins per $\mathrm{m}^{2}$ per $\mathrm{s}$ in the presence of $1 \% \mathrm{CO}_{2}$ in an environmental incubator chamber (Hoffman Manufacturing, Jefferson, OR). Growth medium containing $6 \mathrm{mM}$ ammonia as a nitrogen source $\left(\mathrm{BG}-11\left(\mathrm{NH}_{4}\right)\right.$ ) was prepared as previously described. ${ }^{16}$ To remove combined nitrogen, Anabaena 7120 cultures were washed three times with BG-11 lacking a source of combined nitrogen and resuspended in the same medium. Media were supplemented with streptomycin and spectinomycin at a concentration of $2.5 \mu \mathrm{g} \mathrm{mL} \mathrm{L}^{-1}$ each or neomycin at a concentration of $90 \mu \mathrm{g} \mathrm{mL}^{-1}$ for plasmid selection in Anabaena 7120. Plasmids were introduced into Anabaena 7120 by conjugation from $E$. coli as previously described. ${ }^{17}$ Expression from the copper-inducible pet $E$ promoter was achieved with the addition of copper to a final concentration of 0.2 $\mu \mathrm{M} .{ }^{18}$ For growth curves, $100 \mathrm{~mL}$ BG-11 cultures were inoculated with the Anabaena 7120 strains noted to an initial $\mathrm{OD}_{750} \sim 0.01$ and grown in continuous light shaking at 150 rpm. Measurements were taken daily by diluting the cultures $5 x$ in BG-11 medium and measuring the $\mathrm{OD}_{750}$ on a BioSpectrometer kinetic. Creation of mosaic filaments was conducted as previously described. ${ }^{19}$ Bacteria were handled using aseptic technique and all molecular biology protocols were performed according to standard procedures unless otherwise noted. $^{20}$

\section{Lambda red recombination and transformation-associated recombination (TAR).}

Lambda red recombination was carried out essentially as previously described with a few modifications. ${ }^{4}$ E. coli strain BW25113 carrying pKD46 was made competent using 
standard methods ${ }^{20}$ and fosmid fos-DE3-8 $86^{10}$ harboring the lyngbyatoxin biosynthetic gene cluster was introduced by electroporation. The resulting strain containing pKD46 and fos-DE3-86 was induced with arabinose and made competent as previously described. ${ }^{4}$ Plasmids linearized by PCR for use as prey were size selected on $0.6 \%$ agarose gels and excised, extracted with the Qiagen Gel Extraction Kit, digested with DpnI, purified with the Qiagen PCR Cleanup Kit, and resuspended in MilliQ water. Each reaction contained $50 \mu \mathrm{L}$ of cells containing pKD46 and fos-DE3-86 described above. Introduction of 100-200 ng of linearized plasmid was electroporated using an Eporator (Eppendorf) according to the manufacturer's instructions. Electroporations were recovered in $0.8 \mathrm{~mL}$ of SOC medium and $50 \mu \mathrm{L}$ was spread onto selection plates, which usually generated 10-50 colonies per plate. Nearly every colony screened contained the desired recombination. Growth of the yeast strain VL6-48N, plasmid preparation, and TAR protocol were as previously described. ${ }^{5}$ The efficiency of this protocol was similar for capture vectors linearized by PCR or digestion.

Plasmid construction. The strains and plasmids used in this study are listed in Supplementary Table 12. The primers used in this study are listed in Supplementary Table 13.

Construction of $\mathrm{pET} 28-1 \mathrm{txD}-1$. The $l t x D$ gene was amplified from fosmid fos-DE3-86 $6^{10}$ with PrimeStar GXL polymerase according to the manufacturer's instructions using oligonucleotides ltxDfwd and ltxDrev (Supplementary Table 13) with the following program: $98^{\circ} \mathrm{C}, 30 \mathrm{sec} ; 98^{\circ} \mathrm{C}, 10 \mathrm{sec}, 60^{\circ} \mathrm{C}, 20 \mathrm{sec}, 68^{\circ} \mathrm{C}, 30 \mathrm{sec}$, repeat $30 \mathrm{x} ; 68^{\circ} \mathrm{C}, 2$ $\min ; 4^{\circ} \mathrm{C}$, until use. Visualization on a $1 \%$ agarose gel noted the presence of a single band at approximately $800 \mathrm{bp}$. The PCR product was purified using the QIAquick PCR purification kit and then digested with NdeI and XhoI. The digested product was isolated with the QIAquick PCR purification kit and ligated into the similarly digested pET28a vector using T4 DNA ligase at $16^{\circ} \mathrm{C}$ for $16 \mathrm{~h}$. The ligase was deactivated at $65^{\circ} \mathrm{C}$ for 10 min and then $5 \mu \mathrm{L}$ the mixture was transformed into chemically competent NEB10 $\beta$ cells. The cells were plated on LB agar supplemented with kanamycin and grown at $37^{\circ} \mathrm{C}$ for 16-18 $\mathrm{h}$. Individual colonies were grown up in LB media with kanamycin $(3 \mathrm{~mL}$ volume) and the plasmids were isolated using the QIAprep Spin Miniprep Kit.

Sequencing confirmed that the correct insert was present in plasmid pET28-1txD-1, which was then used for further experiments. All plasmids were constructed in an analogous fashion using the above methods and enzymes.

Synthesis of promoter regions from cyanobacterial natural product clusters. Plasmids

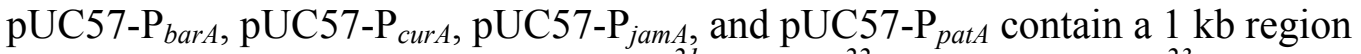
upstream of the first gene in barbamide, ${ }^{21}$ curacin, ${ }^{22}$ and jamaicamide ${ }^{23}$ biosynthetic gene clusters from Moorea producens or $226 \mathrm{bp}$ upstream of the first gene in the patellamide gene cluster from Prochloron didemni, ${ }^{24}$ respectively. Each promoter region was synthesized by GenScript (Piscataway, NJ) and cloned into the EcoRV site of pUC57 to

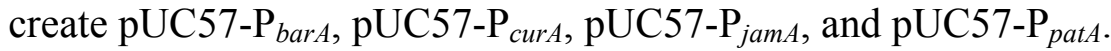

Construction of pPJAV361. Plasmid pPJAV361 is a mobilizable shuttle vector based on pAM504 that contains an $\Omega$ interposon conferring resistance to spectinomycin and streptomycin. The $\mathrm{Sp}^{\mathrm{r}} / \mathrm{Sm}^{\mathrm{r}} \Omega$ interposon was excised from $\mathrm{pDW} 9^{9}$ with HindIII, blunt- 
ended, and cloned into pPJAV $123^{12}$ digested with BglII-NcoI and blunt-ended, which inactivates the nptII gene, to create pPJAV361.

Construction of replicative plasmid containing ltxA-C. Plasmid pPJAV500 is a mobilizable shuttle vector based on pPJAV361 that contains $\mathrm{P}_{l t x A}$-ltxA-C. An $11.3 \mathrm{~kb}$ fragment containing $\mathrm{P}_{l t x A}-l t x A-C$ was amplified by PCR from fos-DE3-86 with the primers PltxA-XhoI-F and ltxC-R. The product was cloned into the SmaI site of pPJAV361 to create pPJAV500.

Construction of plasmids with alternate promoters upstream ltxA-C. Plasmids pPJAV501, pPJAV502, and pPJAV503 are mobilizable shuttle vectors based on pPJAV500 that contain $\mathrm{P}_{\text {petE- }}-l t x A-C, \mathrm{P}_{\text {nir }}$-ltx $A-C$, and $\mathrm{P}_{\text {gln }}$-ltx $A-C$, respectively. The pet $E$, nir $A$, and $g \ln A$ promoter regions were amplified by PCR from Anabaena 7120 chromosomal DNA with the primer pairs PpetE-XhoI-F and PpetE-OEX-R, Pnir-XhoI-F and Pnir-OEX-R, and PglnA-XhoI-F and PglnA-OEX-R, respectively. The N-terminal 934 bp of $l t x A$ was amplified by PCR from fos-DE3-86 with the primer 1txA-int-SmaI-R and either 1txAPpetE-OEX-F, ltxA-Pnir-OEX-F, or ltxA-PglnA-OEX-F. The products were fused to their respective promoter by overlap extension PCR, ${ }^{25}$ digested with XhoI-NdeI, and individually cloned into the SalI-NdeI sites of pPJAV500 to create pPJAV501, pPJAV502, and pPJAV503.

Construction of green fluorescent protein reporter plasmids. Plasmids pPJAV508, pPJAV536, pPJAV537, pPJAV538, pPJAV539, and pPJAV540 are mobilizable shuttle vectors based on pAM $1956^{8}$ carrying the promoter regions of $\operatorname{ltx} A, \operatorname{ltx} D, \operatorname{bar} A, \operatorname{cur} A$, $j a m A$, and $p a t A$, respectively, transcriptionally fused to $g f p$. The promoter regions of $l t x A$ and $l t x D$ were amplified by PCR from fos-DE3-86 and the promoter regions of bar $A$,

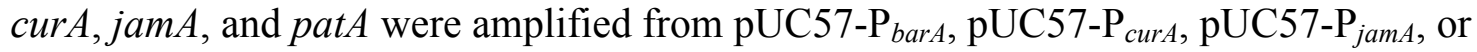

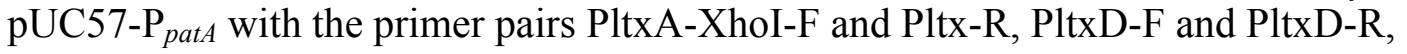
PbarA-F and PbarA-R, PcurA-F and PcurA-R, PjamA-F and PjamA-R, and PpatA-F and PpatA-R, respectively. Each promoter region was cloned into the SmaI site of pAM1956 and directionality was verified by PCR to create pPJAV508, pPJAV536, pPJAV537, pPJAV538, pPJAV539, and pPJAV540.

Construction of pPJAV550. Plasmid pPJAV550 is a mobilizable shuttle vector based on pPJAV361 carrying a yeast element, consisting of an ARSH4/CEN6 oriV and TRP1 marker, for use in TAR cloning. The yeast element was amplified by PCR from pCAP $01{ }^{26}$ with the primers YE-SacI-F and YE-SmaI-R, digested with SacI-SmaI, and cloned into the same sites of pPJAV361 to create pPJAV550.

Construction of plasmids for chloramphenicol acetyltransferase assay. Plasmid pPJAV560 is a mobilizable shuttle vector based on pPJAV361 carrying $\mathrm{P}_{\text {cat }}$-cat. A fragment of DNA containing $\mathrm{P}_{\text {cat }}$ cat, conferring resistance to chloramphenicol via the cat (chloramphenicol acetyltransferase) gene, was amplified by PCR from pACYC184 ${ }^{6}$ with the primers Pcat-F and CAT-SacI-R, digested with SacI, and cloned into the SacISmaI sites of pPJAV361 to create pPJAV560.

Plasmid pPJAV561 is a mobilizable shuttle vector based on pPJAV361 carrying a promoterless cat gene for creating transcriptional fusions with cat. A fragment of DNA containing the coding region of $c$ at was amplified by PCR from pACYC184 with the 
primers CAT-SmaI-F and CAT-SacI-R, digested with SacI-SmaI, and cloned into the same sites of pPJAV361 to create pPJAV561.

Plasmids pPJAV562, pPJAV574, pPJAV575, pPJAV576, pPJAV577, and pPJAV578, pPJAV608, pPJAV609, and pPJAV610 are mobilizable shuttle vectors based on pPJAV561 carrying the promoter regions of $\operatorname{ltx} A, \operatorname{ltx} D, \operatorname{bar} A, \operatorname{cur} A, j a m A, \operatorname{pat} A, \mathrm{P}_{\text {petE }}$, $\mathrm{P}_{\text {nirA }}$, and $\mathrm{P}_{\text {gln }}$, respectively, transcriptionally fused to $c a t$. The promoter regions of $l t x A$ and $l t x D$ were amplified by PCR from fos-DE3-86, the promoter regions of barA, curA,

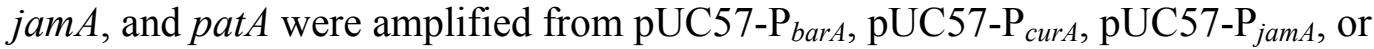
pUC57- $\mathrm{P}_{\text {pat } A}$, and the promoter regions of pet $E$, nir $A$, and $g \ln A$ were amplified from Anabaena 7120 chromosomal DNA with the primer pairs PltxA-XhoI-F and Pltx-R, PltxD-F and PltxD-R, PbarA-F and PbarA-R, PcurA-F and PcurA-R, PjamA-F and PjamA-R, PpatA-F and PpatA-R, PpetE-XhoI-F and PpetE-OEX-R, Pnir-XhoI-F and Pnir-OEX-R, and PglnA-XhoI-F and PglnA-OEX-R, respectively. Each promoter region was individually cloned into the SmaI site of pPJAV561 and directionality was verified by PCR to create pPJAV562, pPJAV574, pPJAV575, pPJAV576, pPJAV577, pPJAV578, pPJAV608, pPJAV609, and pPJAV610.

Creation of replicative vector containing ltxA-C and TRP 1 locus. Plasmid pPJAV568 is a mobilizable shuttle vector based on pPJAV550 carrying $\mathrm{P}_{l t x A}-l t x A-C$. The ltxA promoter region and $\mathrm{C}$-terminal region of $l t x C$ were amplified by PCR from fos-DE3-86 with the primer pairs PltxA-XhoI-F and ltxC-up-ScaI-R and ltxC-dn-ScaI-F and ltxC-R. The products were fused together by overlap extension PCR, cloned into the SmaI site of pJAV550, and directionality was verified by PCR such that $l t x A-C$ did not read into the yeast element. The resulting plasmid was linearized by PCR with the primers ltxC-dnScaI-F and ltxC-up-ScaI-R and electroporated into competent $E$. coli as described above for lambda red recombination to recombineer $l t x A-C$. Resulting transformants were screened by PCR for the presence of $l t x A-C$ in pPJAV550 to create pPJAV568.

Creation of replicative plasmid containing ltx $A-D$. Plasmid pPJAV572 is a mobilizable shuttle vector based on pPJAV550 carrying $\mathrm{P}_{l t x A}-l t x A-D$. The $l t x A$ promoter region and ltx $D$ were amplified by PCR from fos-DE3-86 with the primer pairs PltxA-XhoI-F and ltxD-up-ScaI-R and ltxD-dn-ScaI-F and ltxD-R. The products were fused together by overlap extension PCR, cloned into the SmaI site of pJAV550, and directionality was verified by PCR such that $l t x A-D$ did not read into the yeast element. The resulting plasmid was linearized by PCR with the primers ltxD-dn-ScaI-F and ltxD-up-ScaI-R and electroporated into competent $E$. coli as described above for lambda red recombination to recombineer $l t x A-D$. Resulting transformants were screened by PCR for the presence of ltxA-D in pPJAV550 to create pPJAV572.

Creation of plasmid containing ltxA-D with His 6 tag at C-terminus of LtxD. Plasmid pPJAV612 is a mobilizable shuttle vector based on pPJAV550 carrying $\mathrm{P}_{l t x A}$-ltxA-D with a C-terminal His ${ }_{6}$-tagged LtxD. A region containing the ltx $A$ promoter and $934 \mathrm{bp}$ of $l$ tx $A$ was amplified by PCR from fos-DE3-86 with the primers PltxA-XhoI-F and ltxA-intSmaI-R and ltxD-His6 was amplified from pET28a-ltxD with the primers ltxDFwd and pETseq-. The products were digested with NdeI, cloned into the SmaI site of pBlueScript $\mathrm{SK}+$, and directionality was verified by PCR. A fragment containing $\mathrm{P}_{l t x A}$ and $l t x D$-His6 was amplified from this construct by PCR with the primers PltxA-XhoI-F and pETseq-, cloned into the SmaI site of pPJAV550, and directionality was verified by PCR such that 
ltx $A-D$ did not read into the yeast element. The resulting plasmid was linearized by PCR with the primers ltxDFwd and Pltx-R and was electroporated into competent $E$. coli as described above for lambda red recombination to recombineer ltx $A-D$-His ${ }_{6}$. Resulting transformants were screened by PCR for the presence of $l t x A$-D-His 6 in pPJAV550 to create pPJAV612.

Creation of plasmid containing ltxA-C using TAR. Plasmid pPJAV633 is a mobilizable shuttle vector based on pPJAV550 carrying $\mathrm{P}_{l t x A}-l t x A-C$. The $l t x A$ promoter region and $\mathrm{C}$ terminal region of $l t x C$ were amplified by PCR from fos-DE3-86 with the primer pairs PltxA-XhoI-F and ltxC-up-ScaI-R and ltxC-dn-ScaI-F and ltxC-R. The products were fused together by overlap extension PCR, cloned into the SmaI site of pJAV550, and directionality was verified by PCR such that $l t x A-C$ did not read into the yeast element. The resulting plasmid was linearized by PCR with the primers ltxC-dn-ScaI-F and ltxCup-ScaI-R and utilized for TAR to recombineer $l t x A-C$. Resulting transformants were screened by PCR for the presence of $l t x A-C$ in pPJAV550 to create pPJAV633.

Creation of plasmid containing the entire $M$. producens DNA fragment from fos-DE3-86. Plasmid pPJAV654 is a mobilizable shuttle vector based on pPJAV550 carrying the $\sim 40$ $\mathrm{kb} M$. producens DNA fragment from fos-DE3-86. Regions up- and downstream of the M. producens insert were amplified by PCR from fos-DE3-86 with the primer pairs fosup-F and fos-up-BamHI-R and fos-dn-BamHI-F and fos-dn-EcoRI-R, respectively. The up- and downstream products were digested with either BamHI or BamHI-EcoRI, respectively, and cloned into the SmaI-EcoRI sites of pPJAV550. The resulting plasmid was linearized by digestion with BamHI and utilized for lambda red recombination to recombineer the $M$. producens DNA fragment from fos-DE3-86. Resulting transformants were screened by PCR for the presence of $l t x A-D$ to create pPJAV654. The size of the construct was assessed by electrophoresis on a $0.5 \%$ agarose gel and comparison to the Quick-Load 1kb Extend DNA ladder (New England Biolabs) such that the resulting plasmid was larger than the $48 \mathrm{~kb}$ ladder band.

Chloramphenicol acetyltransferase (CAT) assay. CAT assays were conducted as previously described with minor modifications. ${ }^{27,}{ }^{28}$ Briefly, Anabaena 7120 strains harboring plasmids containing transcriptional fusions to cat were scraped from plates or concentrated from liquid cultures by centrifugation at 2,000 $\mathrm{x} g$ for $3 \mathrm{~min}$ and resuspended in $500 \mu \mathrm{L} 10 \mathrm{mM}$ Tris base $(\mathrm{pH} 7.8)$ to an $\mathrm{OD}_{750} \sim 2.0$. Cell suspensions were sonicated on ice with 6 pulses at 30\% amplitude for $10 \mathrm{~s}$ each using a Qsonica Q55 sonicator and then clarified by centrifugation at $4^{\circ} \mathrm{C}$ for $5 \mathrm{~min}$ at $21,000 \mathrm{x} g$. The supernatant was transferred to a chilled $1.5 \mathrm{~mL}$ microcentrifuge tube and the protein concentration was determined by measuring the $\mathrm{OD}_{280}$ with a BioSpectrometer kinetic. Supernatants were diluted to a final concentration of $0.33 \mu \mathrm{g}$ protein $/ \mu \mathrm{L}$ in cold $10 \mathrm{mM}$ Tris base ( $\mathrm{pH} 7.8)$ and $5 \mu \mathrm{L}$ was mixed by pipetting into $295 \mu \mathrm{L}$ of CAT assay reaction mixture $(270 \mu \mathrm{L} 100 \mathrm{mM}$ Tris base $(\mathrm{pH} 7.8), 10 \mu \mathrm{L}$ of $2.5 \mathrm{mM}$ DTNB in $100 \mathrm{mM}$ Tris base (pH 7.8), $10 \mu \mathrm{L}$ of $5 \mathrm{mM}$ acetyl-CoA, and $5 \mu \mathrm{L}$ of a $0.3 \%(\mathrm{w} / \mathrm{v})$ chloramphenicol solution). The reactions were incubated at $25^{\circ} \mathrm{C}$ in a BioSpectrometer and the $\mathrm{OD}_{412}$ was measured every $10 \mathrm{~s}$ for $2 \mathrm{~min}$. Linear regression lines were fit to the data and the activity in units was determined by comparison to a standard curve created using varying 
activities of purified CAT (Sigma-Aldrich). All data were plotted and analyzed using the GraphPad Prism software (GraphPad, La Jolla, CA).

Microscopy. Anabaena 7120 filaments were routinely viewed with a Zeiss Standard 14 microscope. For fluorescence images, cells were viewed through a Leica HC microscope using a 40x objective or 60x oil objective, and images were captured with a SPOT RT3 digital camera. A Leica FITC L5 filter cube with an excitation of $480 \pm 20 \mathrm{~nm}$ and emission of $527 \pm 15 \mathrm{~nm}$ was used to monitor green fluorescent protein fluorescence. Images were processed in Adobe Photoshop CS3.

RNA isolation and RT-PCR. Anabaena 7120 strains harboring pPJAV500, pPJAV501, pPJAV502, and pPJAV503 were grown on plates or in $30 \mathrm{ml}$ liquid cultures in identical conditions to those used for LTXA production and CAT assays. Cells were scraped from plates or pelleted by centrifugation for $3 \mathrm{~min}$ at 2,000 $\mathrm{x} g$ and the pellets were stored in RNAlater at $-20^{\circ} \mathrm{C}$ until processing. Total RNA was extracted using the RNeasy kit according to the manufacturer's instructions (Qiagen). DNA was removed from the RNA extracts with an in-solution DNase digest and the RNA was cleaned and concentrated with the RNeasy MinElute Cleanup Kit according to the manufacturer's instructions (Qiagen). RNA concentrations were measured using a BioSpectrometer kinetic (Eppendorf) and RNA stability was assessed by visualizing 1 ug of each sample on a 1\% agarose bleach gel. ${ }^{29}$ To verify that all contaminating DNA was removed by DNase digestion, $0.5 \mathrm{ug}$ of RNA from each sample was used as the template for PCR using the primer sets BD16SF1 and BD16SR1 and ltxA1-F and ltxA1-R, respectively, in $20 \mathrm{ul}$ reactions with MangoMix according to the manufacturer's instructions (Bioline, Taunton, MA). The PCR profile was 2 min at $94^{\circ} \mathrm{C}$ followed by 25 cycles of $30 \mathrm{~s}$ at $94^{\circ} \mathrm{C}, 30 \mathrm{~s}$ at $56^{\circ} \mathrm{C}$, and $30^{\circ} \mathrm{S}$ at $72^{\circ} \mathrm{C}$ with a final extension for 2 min at $72^{\circ} \mathrm{C} .{ }^{30}$ All RNA reactions were run on agarose gels and did not display amplified bands from either primer set, which confirmed the absence of contaminating DNA.

About 0.5 ug of RNA from each sample was transcribed into cDNA with the HighCapacity cDNA Reverse Transcription kit according to the manufacturer's instructions (Applied Biosystems, Foster City, CA). All RT-PCRs were performed in MicroAmp Fast Optical 96 well reaction plates (Thermo Fisher Scientific, Eugene, OR) covered with MicroAmp Optical Adhesive film (Thermo Fisher Scientific). RT-PCR reactions were assembled manually and contained $10 \mathrm{pmol}$ of each primer, $25 \mathrm{ng}$ of template cDNA, and $10 \mu \mathrm{l}$ of iTaq Universal SYBR Green Supermix (Bio-Rad) in $20 \mu 1$ reactions. The BD16S primer set was utilized to amplify the $16 \mathrm{~S}$ rRNA as a reference gene because this was shown to be consistently expressed across growth conditions. ${ }^{30}$ cDNA derived from the ltx $A-C$ genes was amplified with the primer sets ltxA-RNA-F1 and ltxA-RNA-R1, ltxARNA-F4 and ltxA-RNA-R4, ltxB-RNA-F and ltxB-RNA-R, and ltxC-RNA-F and ltxCRNA-R as previously described. ${ }^{31}$ The reaction profile was 3 min at $95^{\circ} \mathrm{C}$ followed by 40 cycles of $30 \mathrm{~s}$ at $95^{\circ} \mathrm{C}, 30 \mathrm{~s}$ at $56^{\circ} \mathrm{C}$, and $30 \mathrm{~s}$ at $72^{\circ} \mathrm{C}$. An annealing temperature of $56^{\circ} \mathrm{C}$ was used because this temperature elicited similar amplification levels from all primer sets. Negative controls (no template cDNA) were included and a melting curve analysis was performed in all cases. RT-PCRs were performed with two biological replicates and 
technical triplicate of each cDNA sample in a StepOnePlus Real-Time PCR System (Applied Biosystems). Standard curves were performed with eight two-fold serial dilutions for each primer set in technical triplicate, using purified PCR product as a template. The relative quantities of each sample were calculated using the $\Delta \Delta \mathrm{Ct}$ method, taking into account each primer's specific efficiency calculated from the standard curves. All values were normalized to $16 \mathrm{~S}$ rRNA expression.

\section{Expression and purification of His 6 -LtxD.}

Plasmid pET28a-ltxD-1 was transformed into E. coli BL21(DE3)-T1 ${ }^{\mathrm{R}}$ cells and positive colonies were selected on LB agar plates supplemented with kanamycin. A single colony was inoculated in LB media with kanamycin $(2 \mathrm{~mL})$ and grown overnight at $37^{\circ} \mathrm{C}$ at 200 $\mathrm{rpm}$. A portion of the overnight culture $(0.25 \mathrm{~mL})$ was inoculated into $250 \mathrm{~mL}$ LB media with kanamycin (x2 flasks). The cultures were then grown at $28^{\circ} \mathrm{C}$ for approximately 5.5 $\mathrm{h}$ at $200 \mathrm{rpm}\left(\mathrm{OD}_{600}=0.6-0.8\right)$ and then Isopropyl $\beta$-D-1-thiogalactopyranoside (IPTG) was added to a final concentration of $0.1 \mathrm{mM}$. The cultures were grown for an additional $3.5 \mathrm{~h}$ at $28^{\circ} \mathrm{C}$ at $200 \mathrm{rpm}$ and then the cells were harvested by centrifugation $(3,220 \times \mathrm{g}$, $15 \mathrm{~min}, 4^{\circ} \mathrm{C}$ ). The media was decanted and the cell pellet stored at $-20^{\circ} \mathrm{C}$ until use. The cell pellet was defrosted on ice and resuspended in $20 \mathrm{~mL}$ lysis buffer $(50 \mathrm{mM}$ Tris, 300 $\mathrm{mM} \mathrm{NaCl}, 10 \mathrm{mM}$ imidazole, $\mathrm{pH}$ 8.0). Cells were lysed by sonication with a Qsonica Q55 sonicator at 30\% output, on ice, for 1-2 min on-off cycles that were repeated 4 times. Cell debris was pelleted by centrifugation $\left(13,751 x \mathrm{~g}, 45 \mathrm{~min}, 4^{\circ} \mathrm{C}\right)$. The cleared supernatant was incubated with $0.25 \mathrm{~mL}$ Profinity IMAC resin (Bio-Rad, Hercules, CA), which had been pre-equilibrated with lysis buffer, for $1 \mathrm{~h}$, on ice, $50 \mathrm{rpm}$. The resin was then loaded into a Poly-Prep chromatography column (Bio-Rad) and drained. The resin was washed with $10 \mathrm{~mL}$ lysis buffer and then $3 \times 1 \mathrm{~mL}$ wash buffer (50 mM Tris, 300 $\mathrm{mM} \mathrm{NaCl}, 25 \mathrm{mM}$ imidazole, $5 \mathrm{mM} \beta$-mercaptoethanol, $\mathrm{pH} \mathrm{8.0).} \mathrm{His} 6$-LtxD-His 6 was eluted with successive $0.75,0.25,0.25$ and $0.25 \mathrm{~mL}$ elution buffer $(50 \mathrm{mM}$ Tris, $300 \mathrm{mM}$ $\mathrm{NaCl}, 250 \mathrm{mM}$ imidazole, $5 \mathrm{mM} \beta$-mercaptoethanol, $\mathrm{pH}$ 8.0). Fractions were analyzed by SDS-PAGE gel electrophoresis and fractions containing protein were combined and desalted using an EconoPac 10DG desalting column (Bio-Rad) into desalting buffer (50 $\mathrm{mM}$ Tris, $300 \mathrm{mM} \mathrm{NaCl}, 5 \mathrm{mM} \beta$-mercaptoethanol, $10 \%$ (v/v) glycerol, $\mathrm{pH} 7.5$ ) according to the manufacturer's instructions. The fractions containing protein were flash frozen in liquid nitrogen and stored at $-80^{\circ} \mathrm{C}$ until use.

Western blot analysis. Cultures of wild type Anabaena 7120 harboring either $l$ tx $A$ - $D$ His $_{6}$ (pPJAV612) or the empty control vector (pPJAV361) were scraped from plates and resuspended in $500 \mu \mathrm{L}$ of lysis buffer $(50 \mathrm{mM}$ Tris, $300 \mathrm{mM} \mathrm{NaCl}, 10 \mathrm{mM}$ imidazole, $\mathrm{pH}$ 8.0). Cell suspensions were sonicated on ice with 6 pulses at $30 \%$ amplitude for $10 \mathrm{~s}$ each using a Qsonica Q55 sonicator and then clarified by centrifugation at $4{ }^{\circ} \mathrm{C}$ for $5 \mathrm{~min}$ at $21,000 \times g$. The supernatant was transferred to a chilled $1.5 \mathrm{~mL}$ microcentrifuge tube and the protein concentration was determined by measuring the $\mathrm{OD}_{280}$. Anabaena 7120 lysates containing about $20 \mu \mathrm{g}$ of protein or 25 to $500 \mathrm{ng}$ of purified recombinant His 6 -

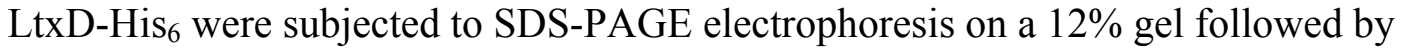
electrophoretic transfer onto an Immobilon P polyvinylidene difluoride membrane (EMD Millipore). LtxD-His6 was detected with primary mouse antihistidine tag antibodies 
(Bio-Rad) and secondary goat anti-mouse horseradish peroxidase (Bio-Rad) conjugated antibodies (Bio-Rad) followed by chemiluminescent detection (Clarity Western ECL Substrate, Bio-Rad) and imaging with a ChemiDoc MP (Bio-Rad).

Extraction of lyngbyatoxin A from Moorea producens. Three aliquots of Moorea producens was collected from Kahala beach in December 2015 and saved in RNAlater (Thermo Fisher Scientific). Cyanobacteria were washed in deionized water and lyophilized in scintillation vials. After lyophilization, dichloromethane and 0.05 grams of $1 \mathrm{~mm}$ diameter zircon beads (VWR, Radnor, PA) were added to each scintillation vial, all of which were then sonicated for one hour in a Branson 3510 sonicator at which time a stir bar was added and the sample was stirred overnight at room temperature. The samples were then sonicated for an additional $30 \mathrm{~min}$ and stirred for four hours at room temperature. Solid material was removed via filtration over a Buchner funnel and filtered solid material was re-extracted as above. The sequential extracts were concentrated in vacuo and combined. Extracts were dissolved in methanol at $10 \mathrm{mg} / \mathrm{mL}$, particulates removed by filtration through a $0.2 \mu \mathrm{m}$ nylon syringe filter, and $10 \mu \mathrm{L}$ injected for quantification by LC-MS/MS as for LTXA produced by Anabaena 7120.

Dichloromethane was utilized in these extractions because the LTXA yield was much greater than from analogous extractions using ethyl acetate.

Purification of lyngbyatoxin A from Anabaena 7120. Ethyl acetate extracts of Anabaena 7120 expressing ltx $A-C$ from 45 plates were dissolved in $11 \mathrm{~mL}$ of methanol. To the deep green solution was added $12 \mathrm{~mL}$ water and upon mixing a precipitate formed. The solution was filtered through $0.45 \mathrm{~mm}$ syringe filters and then applied to a Puriflash PF-C18HP column (6 g, 50 mm, Interchim, Inc., Los Angeles, CA), which had been pre-conditioned with 3 column volumes of methanol followed by 3 column volumes of $50 \%$ aq. methanol. Lyngbyatoxin A was then partially purified using a PuriFlash 450 (Interchim, Inc.) where line $\mathrm{C}$ was water and line $\mathrm{D}$ was methanol. The flow was initially set to $3.6 \mathrm{~mL} / \mathrm{min}$ and was increased to $7 \mathrm{ml} / \mathrm{min}$ over 21 seconds. The initial concentration $(50 \% \mathrm{C} / 50 \% \mathrm{D})$ was maintained for 3:30 min followed by changing the mobile phase to $0 \% \mathrm{C} / 100 \% \mathrm{D}$ over $21 \mathrm{~min}$. This composition was maintained for $21 \mathrm{~min}$ to elute all color from the column. Seven (7) $\mathrm{ml}$ fractions were automatically collected and then concentrated to dryness using a GeneVac rotary concentrator $\left(25^{\circ} \mathrm{C}, 3 \mathrm{~h}\right)$. Fractions were then analyzed for the presence of lyngbyatoxin A by HPLC analysis.

Detection of lyngbyatoxin A by HPLC. Fractions were dissolved in $1 \mathrm{~mL}$ of methanol and $10 \mu \mathrm{L}$ was analyzed by HPLC as follows. HPLC analysis was performed using an Agilent 1100 HPLC system equipped with a quaternary pump, a degasser, an autosampler, a diode array detector, and automated fraction collector (Agilent Technologies, Santa Clara, CA). Separation was achieved using a Chromolith RP-18e column ( $2 \times 100 \mathrm{~mm}$, EMD Millipore) with a flow rate of $0.4 \mathrm{~mL} / \mathrm{min}$, where line $\mathrm{C}$ was water $+0.1 \%$ (vol/vol) formic acid and line $\mathrm{D}$ was methanol $+0.1 \%(\mathrm{vol} / \mathrm{vol})$ formic acid. The column was pre-equilibrated in $95 \% \mathrm{C} / 5 \% \mathrm{D}$ and this composition was maintained for 2 min following injection. The mobile phase was changed to $0 \% \mathrm{C} / 100 \%$ $\mathrm{D}$ over the next 18 min using a linear gradient and then held at this composition for 15 min. The mobile phase was returned to $95 \% \mathrm{C} / 5 \% \mathrm{D}$ over 1 min and the column was equilibrated for $10 \mathrm{~min}$ prior to the next injection. Under these conditions lyngbyatoxin A 
elutes at 21 min. Lyngbyatoxin A was detected in fractions $31-33$. These fractions were combined and lyngbyatoxin A was purified by HPLC.

Purification of lyngbyatoxin A by HPLC. HPLC purification was achieved using the HPLC described above using a Chromolith RP-18e column (4.6 x 100 mm, EMD Millipore) at a flow rate of $2 \mathrm{~mL} / \mathrm{min}$, where line $\mathrm{C}$ was water and line $\mathrm{D}$ was acetonitrile. The column was equilibrated in $60 \% \mathrm{C} / 40 \% \mathrm{D}$ and this concentration was held for $1 \mathrm{~min}$ after injection. The composition was changed to $0 \% \mathrm{C} / 100 \% \mathrm{D}$ over then next 10 min using a linear gradient and this concentration was held for 6 min. The composition was recycled to $60 \% \mathrm{C} / 40 \% \mathrm{D}$ over $1 \mathrm{~min}$ and the column was equilibrated for $5 \mathrm{~min}$ prior to the next injection. The collected samples were concentrated to dryness using a GeneVac rotary concentrator $\left(25^{\circ} \mathrm{C}\right.$ chamber). Samples were stored dry at $-20^{\circ} \mathrm{C}$ until use. Samples were dissolved in methanol and then diluted 1:1 with water. The sample was analyzed using a BioSpectrometer kinetic. The concentration of lyngbyatoxin A was determined by Beer's law using the published extinction coefficient of 9,300 $\mathrm{M}^{-}$ ${ }^{1} \mathrm{~cm}^{-1}$ at $301 \mathrm{~nm}^{1}$

High resolution ESIMS analysis of lyngbyatoxin A. LC-ESITOFMS analysis was performed using an Agilent 1260 HPLC system equipped with a quaternary pump, an autosampler and a 1260 diode array detector upstream of a 6230 TOF mass spectrometer (Agilent Technologies) using a Dual ESI source in positive ionization mode. Separation was achieved using a Zorbax Extend C18, Rapid resolution HT $(2.0$ x 50 mm, $1.8 \mu \mathrm{m}$, Agilent Technologies) with a flow rate of $0.2 \mathrm{~mL} / \mathrm{min}$ where line $\mathrm{C}$ was water $+0.1 \%$ ( vol/vol) formic acid, and line D was acetonitrile $+0.1 \%(\mathrm{vol} / \mathrm{vol})$ formic acid with the following program. The column was pre-equilibrated in $95 \% \mathrm{C} / 5 \% \mathrm{D}$ and upon injection this composition was held for $1 \mathrm{~min}$. The composition of mobile phase was then changed to $0 \% \mathrm{C} / 100 \% \mathrm{D}$ over $30 \mathrm{~min}$ utilizing a linear gradient. This composition was held for $15 \mathrm{~min}$ followed by changing to $95 \% \mathrm{C} / 5 \% \mathrm{D}$ over $1 \mathrm{~min}$. The column was equilibrated in $95 \% \mathrm{C} / 5 \% \mathrm{D}$ for 12 min prior to the next injection. Under these chromatographic conditions, lyngbyatoxin A eluted at $26.1 \mathrm{~min}$. The mass spectrometer had the following settings: Mass range, $100-3000 \mathrm{~m} / \mathrm{z}$ in profile mode utilizing the extended dynamic range (2 GHz); Gas temperature, 325oC; Drying gas, $8 \mathrm{~L} / \mathrm{min}$; Nebulizer, 25 psig; Capillary voltage, $3500 \mathrm{~V}$; Fragmentor, $150 \mathrm{~V}$; Skimmer, $65 \mathrm{~V}$; OCT 1 RF Vpp, $750 \mathrm{~V}$; Acquisition rate, 1 spectra/sec; Time, 1000 ms/spectrum; Transients/spectrum, 9982. Data was processed with MassHunter Workstation software, version B.06.00, build 6.0.633.0 (Agilent Technologies).

\section{References}

[1] Cardellina, J. H., 2nd, Marner, F. J., and Moore, R. E. (1979) Seaweed dermatitis: structure of lyngbyatoxin A, Science 204, 193-195.

[2] Fine Nathel, N. F., Shah, T. K., Bronner, S. M., and Garg, N. K. (2014) Total syntheses of indolactam alkaloids (-)-indolactam V, (-)-pendolmycin, (-)lyngbyatoxin A, and (-)-teleocidin A-2, Chem. Sci. 5, 2184-2190.

[3] Soloveyv, V., and Salamov, A. (2011) Automatic annotation of microbial genomes and metagenomic sequences, In Metagenomics and its applications in agriculture, 
biomedicine and environmental studies (Li, R. W., Ed.), pp 61-78, Nova Science Publishers, hauppauge, NY.

[4] Datsenko, K. A., and Wanner, B. L. (2000) One-step inactivation of chromosomal genes in Escherichia coli K-12 using PCR products, Proc. Natl. Acad. Sci. U.S.A. 97, 6640-6645.

[5] Kouprina, N., and Larionov, V. (2008) Selective isolation of genomic loci from complex genomes by transformation-associated recombination cloning in the yeast Saccharomyces cerevisiae, Nat. Protoc. 3, 371-377.

[6] Rose, R. E. (1988) The nucleotide sequence of pACYC184, Nucleic Acids Res. 16, 355.

[7] Wei, T. F., Ramasubramanian, T. S., and Golden, J. W. (1994) Anabaena sp. strain PCC 7120 ntcA gene required for growth on nitrate and heterocyst development, J. Bacteriol. 176, 4473-4482.

[8] Yoon, H. S., and Golden, J. W. (1998) Heterocyst pattern formation controlled by a diffusible peptide, Science 282, 935-938.

[9] Golden, J. W., and Wiest, D. R. (1988) Genome rearrangement and nitrogen fixation in Anabaena blocked by inactivation of xisA gene, Science 242, 1421-1423.

[10] Edwards, D. J., and Gerwick, W. H. (2004) Lyngbyatoxin biosynthesis: Sequence of biosynthetic gene cluster and identification of a novel aromatic prenyltransferase, J. Am. Chem. Soc. 126, 11432-11433.

[11] Baba, T., Ara, T., Hasegawa, M., Takai, Y., Okumura, Y., Baba, M., Datsenko, K. A., Tomita, M., Wanner, B. L., and Mori, H. (2006) Construction of Escherichia coli $\mathrm{K}-12$ in-frame, single-gene knockout mutants: the Keio collection, Mol. Syst. Biol. 2, 2006.0008.

[12] Rivers, O. S., Videau, P., and Callahan, S. M. (2014) Mutation of sepJ reduces the intercellular signal range of a het $N$-dependent paracrine signal, but not of a patSdependent signal, in the filamentous cyanobacterium Anabaena sp. strain PCC 7120, Mol. Microbiol. 94, 1260-1271.

[13] Black, T. A., Cai, Y., and Wolk, C. P. (1993) Spatial expression and autoregulation of hetR, a gene involved in the control of heterocyst development in Anabaena, Mol. Microbiol. 9, 77-84.

[14] Buikema, W. J., and Haselkorn, R. (1991) Characterization of a gene controlling heterocyst differentiation in the cyanobacterium Anabaena 7120, Genes Dev. 5, 321-330.

[15] Rippka, R., Deruelles, J., Waterbury, J. B., Herdman, M., and Stanier, R. Y. (1979) Generic assignments, strain histories and properties of pure cultures of cyanobacteria, Microbiology 111, 1-61.

[16] Mitschke, J., Vioque, A., Haas, F., Hess, W. R., and Muro-Pastor, A. M. (2011) Dynamics of transcriptional start site selection during nitrogen stress-induced cell differentiation in Anabaena sp. PCC 7120, Proc. Natl. Acad. Sci. U.S.A. 108, 20130-20135.

[17] Elhai, J., and Wolk, C. P. (1988) [83] Conjugal transfer of DNA to cyanobacteria, In Methods in Enzymology, pp 747-754, Academic Press.

[18] Buikema, W. J., and Haselkorn, R. (2001) Expression of the Anabaena hetR gene from a copper-regulated promoter leads to heterocyst differentiation under repressing conditions, Proc. Natl. Acad. Sci. U.S.A. 98, 2729-2734. 
[19] Risser, D. D., and Callahan, S. M. (2008) HetF and PatA control levels of hetR in Anabaena sp. strain PCC 7120, J. Bacteriol. 190, 7645-7654.

[20] Sambrook, J., and Russell, D. (2001) Molecular Cloning: A Laboratory Manual, Cold Spring Harbor Labs Publishing.

[21] Chang, Z., Flatt, P., Gerwick, W. H., Nguyen, V.-A., Willis, C. L., and Sherman, D. H. (2002) The barbamide biosynthetic gene cluster: a novel marine cyanobacterial system of mixed polyketide synthase (PKS)-non-ribosomal peptide synthetase (NRPS) origin involving an unusual trichloroleucyl starter unit, Gene 296, 235247.

[22] Chang, Z., Sitachitta, N., Rossi, J. V., Roberts, M. A., Flatt, P. M., Jia, J., Sherman, D. H., and Gerwick, W. H. (2004) Biosynthetic pathway and gene cluster analysis of curacin A, an antitubulin natural product from the tropical marine cyanobacterium Lyngbya majuscula, J. Nat. Prod. 67, 1356-1367.

[23] Edwards, D. J., Marquez, B. L., Nogle, L. M., McPhail, K., Goeger, D. E., Roberts, M. A., and Gerwick, W. H. (2004) Structure and biosynthesis of the jamaicamides, new mixed polyketide-peptide neurotoxins from the marine cyanobacterium Lyngbya majuscula, Chem. Biol. 11, 817-833.

[24] Schmidt, E. W., Nelson, J. T., Rasko, D. A., Sudek, S., Eisen, J. A., Haygood, M. G., and Ravel, J. (2005) Patellamide A and C biosynthesis by a microcin-like pathway in Prochloron didemni, the cyanobacterial symbiont of Lissoclinum patella, Proc. Natl. Acad. Sci. U.S.A. 102, 7315-7320.

[25] Higuchi, R., Krummel, B., and Saiki, R. (1988) A general method of in vitro preparation and specific mutagenesis of DNA fragments: study of protein and DNA interactions, Nucleic Acids Res. 16, 7351-7367.

[26] Yamanaka, K., Reynolds, K. A., Kersten, R. D., Ryan, K. S., Gonzalez, D. J., Nizet, V., Dorrestein, P. C., and Moore, B. S. (2014) Direct cloning and refactoring of a silent lipopeptide biosynthetic gene cluster yields the antibiotic taromycin A, Proc. Natl. Acad. Sci. U.S.A. 111, 1957-1962.

[27] Day, P. J., and Shaw, W. V. (1992) Acetyl coenzyme A binding by chloramphenicol acetyltransferase. Hydrophobic determinants of recognition and catalysis, J. Biol. Chem. 267, 5122-5127.

[28] Shaw, W. V. (1975) Chloramphenicol acetyltransferase from chloramphenicolresistant bacteria, In Methods in Enzymology (John, H. H., Ed.), pp 737-755, Academic Press.

[29] Aranda, P. S., LaJoie, D. M., and Jorcyk, C. L. (2012) Bleach gel: a simple agarose gel for analyzing RNA quality, Electrophoresis 33, 366-369.

[30] Pinto, F., Pacheco, C., Ferreira, D., Moradas-Ferreira, P., and Tamagnini, P. (2012) Selection of suitable reference genes for RT-qPCR analyses in cyanobacteria, PLoS One 7, e34983.

[31] Jones, A. C., Ottilie, S., Eustáquio, A. S., Edwards, D. J., Gerwick, L., Moore, B. S., and Gerwick, W. H. (2012) Evaluation of Streptomyces coelicolor A3(2) as a heterologous expression host for the cyanobacterial protein kinase $\mathrm{C}$ activator lyngbyatoxin A, FEBS J. 279, 1243-1251. 